\section{Experimental and Theoretical Study of the Complexation of} Cesium and Thallium Cations by a Water-soluble Cryptophane

\author{
Laure-Lise Chapellet, ${ }^{[\mathrm{a}]}$ Jean-Pierre Dognon, ${ }^{*,[\mathrm{~b}]}$ \\ Marion Jean, ${ }^{[\mathrm{c}]}$ Nicolas Vanthuyne, ${ }^{[\mathrm{c}]}$ Patrick \\ Berthault $^{[\mathrm{b}]} \quad$ Thierry Buffeteau, ${ }^{*},[\mathrm{~d}]$ Thierry \\ Brotin $^{*}[\mathrm{a}]$
}

\begin{abstract}
Cs (cesium) and TI (thallium) are known to be very toxic for the environment and human health. Thus, the synthesis of molecular receptors aimed at extracting these two elements from the environment is strongly desired. In this Article, we report the synthesis of the two enantiomers of cryptophane$223(\mathrm{OH})_{7}(1)$ and the study of their interaction with cesium and thallium cations in basic aqueous solutions. These two complexes have been studied by ${ }^{133} \mathrm{Cs}$ and ${ }^{205} \mathrm{TI}$ NMR spectroscopy to reveal the complexation of the two metallic cations and by chiroptical techniques (electronic and vibrational circular dichroism) to provide valuable information about the conformational changes occurring during the binding process. The thermodynamic parameters of complexation $K, \Delta H^{0}$ and $\Delta S^{0}$ obtained from titration experiments reveal a strong interaction between 1 and the two cations under a large range of experimental conditions. A decomposition of the total binding energy, performed by DFT calculations, allows us to characterize the nature of the interactions existing between the cage-molecule and these two cations. These calculations also reveal the importance of the spin-orbit coupling for predicting correctly the large frequency difference between the free $\mathrm{TI}^{+}$and $\mathrm{TI}^{+} @ 1$ NMR signals and to understand its origin. In addition to the development of a methodology enabling detailed understanding of the host-guest interaction, this study indicates a very pronounced selectivity of this cage-molecule towards both $\mathrm{Cs}^{+}$and $\mathrm{TI}^{+}$cations in various experimental conditions.
\end{abstract}

[a] Dr. T. Brotin, Dr. L.L. Chapellet

Laboratoire de Chimie de L'ENS LYON (UMR 5182)

Ecole Normale Supérieure de Lyon

46 , Allée D'Italie

69364 Lyon cedex 07, France

E-mail: thierry.brotin@ens-lyon.fr

[b] Dr. P. Berthault, Dr. J.-P. Dognon NIMBE, CEA, CNRS

Paris-Saclay University, CEA Saclay

91191 Gif-sur-Yvette, France

E-mail: jean-pierre.dognon@cea.fr

[c] M. Jean, Dr. N. Vanthuyne

Aix-Marseille University, CNRS, Centrale Marseille, iSm2 Marseille, France

[d] Dr. T. Buffeteau

Bordeaux University

Institut des Sciences Moléculaires, CNRS UMR 5255

33405 Talence, France

E-mail: t.buffeteau@ism.u-bordeaux1.fr

Supporting information for this article is given at the end of the document.
Introduction Since the previous century, extraction of toxic ions from aqueous solutions by dedicated host molecules is a subject of intense research. During the last decade, we have reported that water-soluble cryptophanes possess remarkable binding properties for a large variety of guest molecules (halogenomethanes, oxiranes and cationic species). ${ }^{[1]}$ For instance, the efficient binding of cesium $\left(\mathrm{Cs}^{+}\right)$and thallium $\left(\mathrm{Tl}^{+}\right)$ cations with water-soluble cryptophanes bearing phenol groups has been evidenced in $\mathrm{LiOH} / \mathrm{H}_{2} \mathrm{O}, \mathrm{NaOH} / \mathrm{H}_{2} \mathrm{O}$ and even in $\mathrm{KOH} / \mathrm{H}_{2} \mathrm{O}$ solutions. Thus, it has been shown that cryptophanes 2, 3, 4 and 5 (Scheme 1) are among the best-known molecular receptors for encapsulating cesium and thallium cations in aqueous solutions. The affinity of $\mathrm{Cs}^{+}$and $\mathrm{TI}^{+}$for these host molecules depends on external parameters (nature of the basic solution, concentration) but also the nature of the cryptophane structure. For instance, it has been clearly established that the presence of phenol groups and their number play a key role in the stabilization of these complexes. This suggests that coulombic interactions probably play an important role in their stabilization. Other types of interactions such as $\pi$-cation interaction probably exist but these different contributions are difficult to quantify without the use of quantum chemistry calculations.

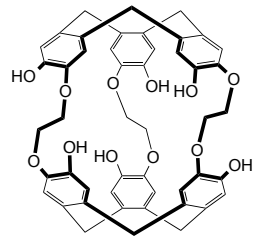

2

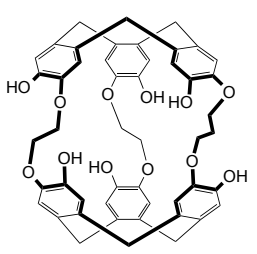

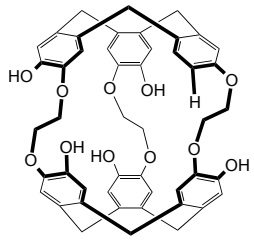

3

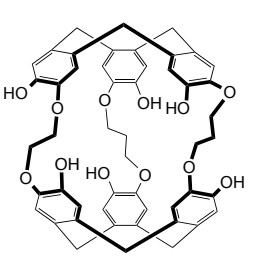

Scheme 1. Chemical structures of water-soluble cryptophanes $(\mathrm{OH})_{\mathrm{x}}(\mathrm{x}=5,6)$ 2-5 used previously for $\mathrm{Cs}^{+}$and $\mathrm{Tl}^{+}$encapsulation.

It has been also reported that cryptophane with larger inner cavities can bind efficiently $\mathrm{Cs}^{+}$and $\mathrm{Tl}^{+}$cations. For instance, compound 4 , which possesses two ethylenedioxy and one propylenedioxy bridges shows a strong affinity for these two cations. Interestingly, the structure of this cryptophane can be modified to introduce a reactive function on the propylenedioxy linker. ${ }^{[2]}$ This chemical group can be chosen in order to react orthogonally with the other groups grafted on the benzene rings.

Cryptophane 1 reported in this article (Scheme 2) belongs to this class of compounds. It contains a secondary alcohol function attached on the propylenedioxy linker and the synthesis of 1 in its racemic form has been recently described. ${ }^{[2]}$ Herein, we report the synthesis of the two enantiomers MM-1 and PP-1 and their characterization by ${ }^{1} \mathrm{H},{ }^{13} \mathrm{C}$ NMR and high-resolution mass spectrometry. We show that compound 1 binds very efficiently $\mathrm{Cs}^{+}$and $\mathrm{TI}^{+}$cations in $\mathrm{LiOH} / \mathrm{H}_{2} \mathrm{O}, \mathrm{NaOH} / \mathrm{H}_{2} \mathrm{O}$ and $\mathrm{KOH} / \mathrm{H}_{2} \mathrm{O}$. Electronic (ECD) and vibrational (VCD) circular dichroism techniques are used to investigate the conformational changes occurring during the binding process. Isothermal titration experiments (ITC) enable accurate determination of the parameters of complexation $\left(K, \Delta H^{0}, \Delta S^{0}\right)$. In addition, ${ }^{133} \mathrm{Cs}$ and ${ }^{205} \mathrm{TI}$ NMR spectroscopy give valuable information on the 
chemical environment of these two cations encapsulated into the cavity of the cage. Finally, we use DFT calculations and decomposition of the total binding energy to investigate and quantify the nature of the interactions that exist between these two cations and host 1.

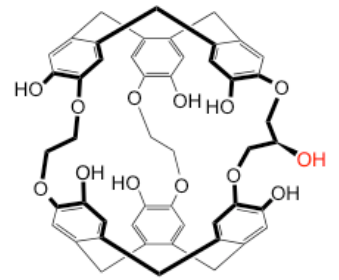

Scheme 2. Structure of the water-soluble cryptophane MM-1.

\section{Results}

Preparation of enantiopure cryptophane 1. Optically active cryptophane 1 has been prepared in a three-steps synthesis from cryptophane $\mathbf{6}$ whose synthesis has been reported recently in its racemic form. ${ }^{[2]}$ The two enantiomers of 6 have been separated by semi-preparative chiral HPLC chromatography to give rise to enantiomers $(-)-6$ and $(+)-6$. The enantiomeric excess of (-)-6 and (+)-6 (ee > 99.5\%) has been checked by analytical HPLC chromatography (Figure S1 in the Supporting Information). Additional purification steps on silica gel and recrystallization in $\mathrm{CH}_{2} \mathrm{Cl}_{2} / \mathrm{EtOH}$ provide these two enantiomers with high chemical purity. The ECD spectra recorded in $\mathrm{CH}_{2} \mathrm{Cl}_{2}$ and $\mathrm{CHCl}_{3}$ and polarimetric measurements (in $\mathrm{CHCl}_{3}$ ) of the two enantiomers (-)-6 and (+)-6 are reported (Figure S2 in the Supporting Information). According to the ECD spectra and polarimetric values obtained for compounds 2-5, we found the following assignment (-)-MM-6 and (+)-PP-6 for the two enantiomers of 6 .

Lithium diphenylphosphide (1 $\mathrm{M}$ in THF) has proved to be a very efficient reagent to deprotect in a single step both the six methyl groups and the allyl function attached on the propylenedioxy linker ${ }^{[2,3,4]}$ Applied to compounds MM-6 and $P P$ 6, this approach gives rise the two desired $M M-1$ and $P P-1$ derivatives in 97 and $99 \%$ yields (crude product), respectively. Since the two isolated compounds $M M-1$ and $P P-1$ contain impurities in small amount, an additional purification has been used. Thus, these two compounds have been allowed to react with anhydride acetic in pyridine to give cryptophanes $M M-7$ and $P P-7$ in $99 \%$ and $78 \%$ after purification, respectively. Then, $M M-1$ and $P P-1$ derivatives have been recovered in $98 \%$ and $92 \%$ yields, respectively by hydrolysis of the ester group under basic conditions (Scheme 3 ). The ${ }^{1} \mathrm{H}$ and ${ }^{13} \mathrm{C}$ NMR spectra of compounds $M M-1$ and $P P-1$ are identical to those previously reported for the racemic derivative (Figures S3-S6 in the Supporting Information). ${ }^{1} \mathrm{H}$ and ${ }^{13} \mathrm{C}$ NMR spectra of MM-7 and PP-7 are also reported (Figures S7-S11 in the Supporting Information). It is noteworthy that compound $\mathbf{7}$ may exist under imploded form, which is ascertained by the presence of characteristic signals in the ${ }^{1} \mathrm{H}$ NMR spectrum. ${ }^{[5,1 c]}$ As an example, the ${ }^{1} \mathrm{H}$ NMR spectrum of a sample containing mainly the imploded form is given (Figure $\mathrm{S} 8$ in the Supporting Information)

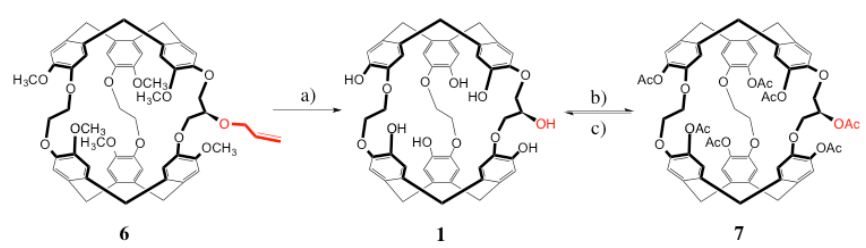

Scheme 3. Synthesis of the two enantiomers of cryptophanes 1 and 7 obtained from the two enantiomers of cryptophane 6. a) $\mathrm{PPh}_{2} \mathrm{Li}(1 \mathrm{M})$, THF, $60^{\circ} \mathrm{C}, 48 \mathrm{hrs} ;(97 \%, \mathrm{MM}-1 ; 99 \%, P P-1)$ b) $\mathrm{Ac}_{2} \mathrm{O}$, Pyridine, $0^{\circ} \mathrm{C}-20^{\circ} \mathrm{C}, 5 \mathrm{hrs}$ $(99 \%, M M-7,78 \%, P P-7)$; c) $\mathrm{KOH}(0.5 \mathrm{M})$, THF, $50^{\circ} \mathrm{C}, 16 \mathrm{~h},(98 \%, M M-1$; $92 \%, P P-1)$

Isothermal Titration Calorimetry (ITC). ITC is the method of choice to measure the association constants between cesium and thallium cations with host 1 in aqueous solutions. In the past, we have used this method to determine the binding constant $K$ and the thermodynamic parameters of complexation $\Delta H^{0}, \Delta S^{\circ}$ and $\Delta G^{0}$ of $\mathrm{Cs}^{+}$and $\mathrm{TI}^{+}$cations with compounds $2-5{ }^{[6]}$ ITC experiments of (rac)-1 in the presence of $\mathrm{Cs}^{+}, \mathrm{Tl}^{+}$and $\mathrm{Rb}^{+}$have been performed in $\mathrm{LiOH} / \mathrm{H}_{2} \mathrm{O}, \mathrm{NaOH} / \mathrm{H}_{2} \mathrm{O}$ and $\mathrm{KOH} / \mathrm{H}_{2} \mathrm{O}$ solutions at different concentrations $(0.1$ or $1.0 \mathrm{M}$ ) (Figures $\mathrm{S} 12-$ $\mathrm{S} 15$ in the Supporting Information). Basic conditions are mandatory to ensure a good solubility of the cage. To interpret the data obtained from isothermal titration calorimetric (ITC) experiments, we will consider that, in our experimental conditions, only the encapsulation of the metallic cations by the molecular host takes place. Example of such an equation reaction is reported in Scheme 4 that describes the encapsulation of different metal cations $\left(\mathrm{M}^{+}=\mathrm{Rb}^{+}, \mathrm{Cs}^{+}, \mathrm{Tl}^{+}\right)$by host 1 in $\mathrm{NaOH} / \mathrm{H}_{2} \mathrm{O}$. The binding constants of $\mathrm{Rb}^{+} @(\mathrm{rac})-\mathbf{1}$, $\mathrm{Cs}^{+} @(\mathrm{rac})-1$ and $\mathrm{Tl}^{+} @(\mathrm{rac})-1$ complexes are reported in Table 1 whereas the thermodynamic parameters of complexation $\Delta H^{0}$, $\Delta S^{0}$ and $\Delta G^{0}$ are given in Supporting Information (Figure $S 16$ in the Supporting Information). Even though $\mathrm{Cs}^{+}$and $\mathrm{TI}^{+}$are the two main cations of interest in this study, the association constant between $\mathrm{Rb}^{+}$and the cage has been measured in some cases to perform competition experiments for high values of $K$.

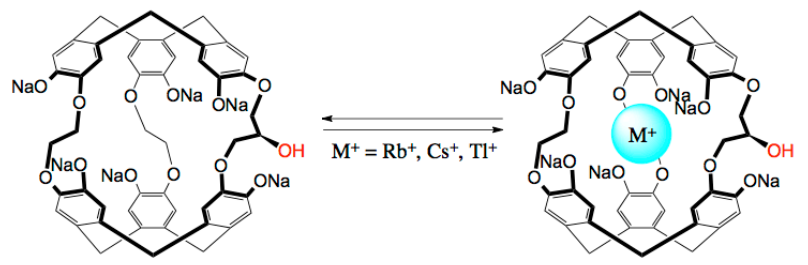

Scheme 4. One binding site model considered for the isothermal titration calorimetric experiments (ITC) in $\mathrm{NaOH} / \mathrm{H}_{2} \mathrm{O}$.

In $\mathrm{LiOH} / \mathrm{H}_{2} \mathrm{O}$ solution at $298 \mathrm{~K}$, the ITC experiments show a very strong association between the $\mathrm{Cs}^{+}$and $\mathrm{TI}^{+}$cations and the cage, even at high concentration. For instance, in $\mathrm{LiOH} / \mathrm{H}_{2} \mathrm{O}$ $(0.1 \mathrm{M})$, an association constant $K=3.6 \times 10^{8} \mathrm{M}^{-1}\left(\Delta G^{0}=-11.7\right.$ kcal mol ${ }^{-1}$ ) has been measured for the $\mathrm{Cs}^{+} @(\mathrm{rac})-1$ complex. At higher $\mathrm{LiOH} / \mathrm{H}_{2} \mathrm{O}$ concentration $(1 \mathrm{M})$, this binding constant is decreased by 2 orders of magnitude $\left(K=4.5 \times 10^{6} \mathrm{M}^{-1} ; \Delta G^{0}=-\right.$ $\left.9.1 \mathrm{kcal} \mathrm{mol}^{-1}\right)$. It is noteworthy that, in the same experimental conditions, the $\mathrm{TI}^{+}$cation shows higher affinity for the cage. For instance, a binding constant $K=1.0 \times 10^{9} \mathrm{M}^{-1}\left(\Delta G^{0}=-13.6 \mathrm{kcal}\right.$ $\mathrm{mol}^{-1}$ ) has been measured in $\mathrm{LiOH} / \mathrm{H}_{2} \mathrm{O}(0.1 \mathrm{M})$. As observed for the $\mathrm{Cs}^{+}$cation, increasing the $\mathrm{LiOH} / \mathrm{H}_{2} \mathrm{O}$ concentration results in a decrease of the binding constant $\left(K=3.1 \times 10^{7} \mathrm{M}^{-1} ; \Delta G^{0}=-10.2\right.$ kcal $\left.\mathrm{mol}^{-1}\right)$. On the other hand, the $\mathrm{Rb}^{+} @(r a c)-1$ complex exhibits much lower association constants under the same experimental conditions. It must be mentioned that the $\mathrm{K}^{+}$cation 
shows also a moderate affinity for the cavity of 1 . For instance, the binding constant has been measured to be $K=1000 \mathrm{M}^{-1}$ in $\mathrm{LiOH} / \mathrm{H}_{2} \mathrm{O}(0.1 \mathrm{M})$.

Table 1. Binding constants $K\left(\mathrm{M}^{-1}\right)$ measured at $298 \mathrm{~K}$ by ITC for the $\mathrm{M}^{+} @(\mathrm{rac})-1$ complexes in LiOH $\left(0.1 \mathrm{M}\right.$ in $\left.\mathrm{H}_{2} \mathrm{O}\right), \mathrm{NaOH}\left(0.1 \mathrm{M}\right.$ in $\left.\mathrm{H}_{2} \mathrm{O}\right), \mathrm{KOH}$ (0.1 $\mathrm{M}$ in $\left.\mathrm{H}_{2} \mathrm{O}\right)$ and $\mathrm{LiOH}\left(1 \mathrm{M}\right.$ in $\left.\mathrm{H}_{2} \mathrm{O}\right)$.

\begin{tabular}{lcccc}
\hline $\begin{array}{l}\text { Cations } \\
\mathrm{M}+\end{array}$ & $\mathrm{LiOH}(0.1 \mathrm{M})$ & $\mathrm{NaOH}(0.1 \mathrm{M})$ & $\mathrm{KOH}(0.1 \mathrm{M})$ & $\mathrm{LiOH}(1 \mathrm{M})$ \\
\hline $\mathrm{Cs}^{+}$ & $3.6 \pm 0.2 \times 10^{8[\mathrm{a}]}$ & $7.6 \pm 0.6 \times 10^{8[a]}$ & $1.0 \pm 0.04 \times 10^{7}$ & $4.5 \pm 0.2 \times 10^{6}$ \\
$\mathrm{TI}^{+}$ & $1.0 \pm 0.1 \times 10^{9[\mathrm{a}]}$ & $11.0 \pm 2 \times 10^{9[\mathrm{a}]}$ & $5.6 \pm 0.9 \times 10^{7}$ & $3.1 \pm 0.2 \times 10^{7}$ \\
$\mathrm{Rb}^{+}$ & $1.3 \pm 0.3 \times 10^{5}$ & $2.6 \pm 0.1 \times 10^{5}$ & - & $1.8 \pm 0.2 \times 10^{3}$ \\
\hline
\end{tabular}

[a] from competition experiments (competitor $\mathrm{Rb}^{+}$)

Replacing the $\mathrm{LiOH}$ solution by a $\mathrm{NaOH}$ solution leads to a slightly higher $K$ value. For instance, in a $0.1 \mathrm{M} \mathrm{NaOH}$ solution, the $\mathrm{Cs}^{+} @(\mathrm{rac})-1$ complex shows a binding constant $K=7.6 \times 10^{8}$ $\mathrm{M}^{-1}\left(\Delta \mathrm{G}^{0}=-12.1 \mathrm{kcal} \mathrm{mol}^{-1}\right)$ slightly higher than that measured in the same conditions in $\mathrm{LiOH}$ solution. The same trend occurs for the $\mathrm{TI}^{+} @(\mathrm{rac})-1$ complex. In contrast to what is observed in these solutions, the use of a $0.1 \mathrm{M} \mathrm{KOH}$ solution has a strong impact on the equilibrium constants of these two complexes. For instance, binding constants $K=1.0 \times 10^{7} \mathrm{M}^{-1}\left(\Delta G^{0}=-9.6 \mathrm{kcal}\right.$ $\left.\mathrm{mol}^{-1}\right)$ and $K=5.6 \times 10^{7} \mathrm{M}^{-1}\left(\Delta G^{0}=-10.6 \mathrm{kcal} \mathrm{mol}^{-1}\right)$ have been measured for the $\mathrm{Cs}^{+} @(\mathrm{rac})-1$ and $\mathrm{Tl}^{+} @(\mathrm{rac})-1$ complexes, respectively. Combined together these results show that both $\mathrm{Cs}^{+}$and $\mathrm{TI}^{+}$cations are very well recognized under a large range of experimental conditions. A very high selectivity toward $\mathrm{Li}^{+}$, $\mathrm{Na}^{+}$and even $\mathrm{K}^{+}$cations is also observed.

${ }^{133} \mathrm{Cs}$ and ${ }^{205} \mathrm{TI}$ NMR Spectroscopy. As both cesium and thallium nuclei have non-null spin isotopes, NMR spectroscopy can be used to characterize the $\mathrm{Cs}^{+} @(\mathrm{rac})-\mathbf{1}$ and $\mathrm{TI}^{+} @(\mathrm{rac})-1$ complexes. Thanks to the high polarizability of their electron clouds and the strong shielding effect induced by the six aromatic rings, high field NMR signals characteristic of the encapsulated form of these cations are observed.

The ${ }^{133} \mathrm{Cs}$ NMR spectrum of $\mathrm{Cs}^{+}$in the presence of $(\mathrm{rac})-1$ shows two well-resolved signals at $298 \mathrm{~K}$ in $\mathrm{NaOD} / \mathrm{D}_{2} \mathrm{O}(0.1 \mathrm{M})$ solution. $\mathrm{Cs}^{+}$free in solution gives an intense signal near $0 \mathrm{ppm}$ whereas the $\mathrm{Cs}^{+} @(\mathrm{rac})-\mathbf{1}$ complex gives rise to a characteristic ${ }^{133} \mathrm{Cs}$ NMR signal located at $\delta=-258 \mathrm{ppm}$. This signal is relatively broad at room temperature. Interestingly, a sharpening of the $\mathrm{Cs}^{+} @(\mathrm{rac})-1$ NMR signal is observed when the temperature of the solution increases (Figure S17 in the Supporting Information). In contrast, lowering the temperature results in a broadening of the $\mathrm{Cs}^{+} @(\mathrm{rac})-1$ NMR signal. This counter-intuitive effect has been previously observed with cryptophanes 2, 3 and 4, which also show a very high affinity for $\mathrm{Cs}^{+}$

The ${ }^{205}$ TI NMR spectra are more difficult to record since this nucleus resonates at a frequency out of the scope of most of the commercial NMR probe heads. Consequently, a homemade system is necessary to facilitate the detection of this signal (see Experimental Section in the Supporting Information for more details). In addition, the detection of the $\mathrm{TI}^{+} @ 1$ signal is made difficult due to the large difference of chemical shift existing between the $\mathrm{Tl}^{+}$cation present within the cavity of the cryptophane host and $\mathrm{TI}^{+}$dissolved in the bulk. In the present case, a high field shifted signal located at $-680 \mathrm{ppm}$ has been observed for the $\mathrm{Tl}^{+} @(\mathrm{rac})-1$ complex. Another signal located at $+340 \mathrm{ppm}$ has been detected for the free $\mathrm{TI}^{+}$cation. This leads to a chemical shift difference larger than $1000 \mathrm{ppm}$ for this system. It is noteworthy that in the case of the TI element, a slight modification in the chemical structure of the host can induce large chemical shift differences. This is evidenced in Figure 1 by comparing the ${ }^{205} \mathrm{TI}$ NMR signals of two $\mathrm{TI}^{+} @(\mathrm{rac})-\mathbf{1}$ and $\mathrm{TI}^{+} @(\mathrm{rac})-\mathbf{4}$, which differ only by the presence of a secondary alcohol function attached on propylenedioxy linkers in host 1.

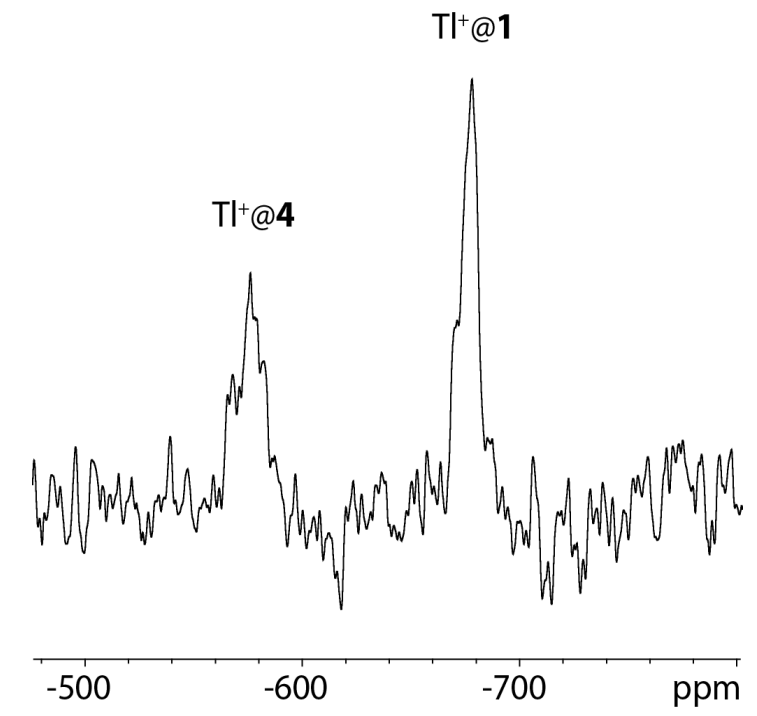

Figure 1. ${ }^{205} \mathrm{TI}$ NMR spectrum of the $\mathrm{TI}^{+} @ 4$ and $\mathrm{TI}^{+} @ 1$ complexes in $\mathrm{NaOD} / \mathrm{D}_{2} \mathrm{O}(0.1 \mathrm{M})$ at $348 \mathrm{~K}$. The free $\mathrm{TI}^{+}$signal is positioned at $340 \mathrm{ppm}$ with respect to $\mathrm{TINO}_{3}$ (not shown). ${ }^{[7]}$

ECD Spectroscopy. Thanks to the preparation of enantiopure compounds $M M-1$ and $P P-1$, the encapsulation process of $\mathrm{Cs}^{+}$ and $\mathrm{TI}^{+}$cations can also be studied using chiroptical techniques such as ECD. This technique is known to be a valuable tool to study the conformational rearrangements that take place in solution upon the encapsulation process. Indeed, large spectral changes are sometimes observed. ECD spectra of the $\mathrm{Cs}^{+} @ M M-1$ and $\mathrm{Tl}^{+} @ M M-$ 1 complexes in $\mathrm{LiOH} / \mathrm{H}_{2} \mathrm{O}(0.1 \mathrm{M})$ in the presence of different amounts of $\mathrm{Cs}^{+}$and $\mathrm{TI}^{+}$cations are presented in Figure 2 .

Figure 2 shows that the addition of various quantities of a cesium hydroxide solution (from 0 to 1 equiv.) to the $\mathrm{LiOH} / \mathrm{H}_{2} \mathrm{O}$ $(0.1 \mathrm{M})$ solution of free host 1 gives rise to a significant change of the overall ECD spectrum in the $220-380 \mathrm{~nm}$ region. The presence of three isosbestic points indicates the formation of a new species upon addition of $\mathrm{Cs}^{+}$. This new species can be attributed to the formation of the $\mathrm{Cs}^{+} @ M M-1$ complex. Replacing the $\mathrm{Cs}^{+}$cation by $\mathrm{Tl}^{+}$cation leads to more marked modifications of the ECD spectra. These spectral changes mainly occur for the ECD bands of the ${ }^{1} L_{b}$ transition $(280-320 \mathrm{~nm})$ for which addition of one equivalent of $\mathrm{Tl}^{+}$results in a significant bathochromic shift. As observed with $\mathrm{Cs}^{+}$, the ECD spectra also reveal the presence of multiple isosbestic points indicating the formation of the $\mathrm{TI}^{+} @ M M-1$ complex. 

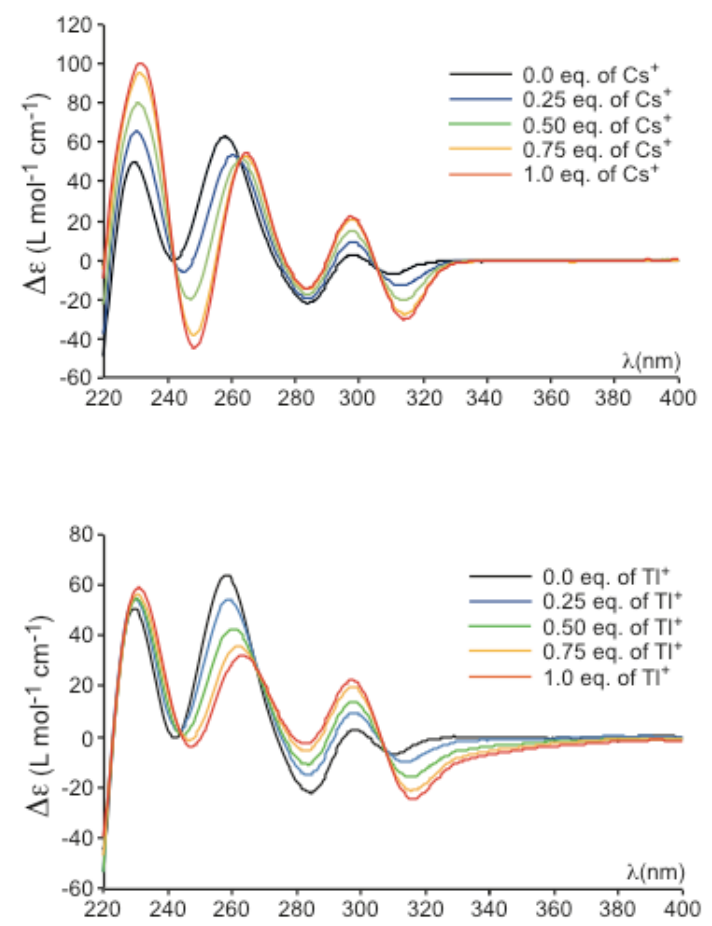

Figure 2. ECD spectra of the $\mathrm{Cs}^{+} @ M M-1$ (top spectra) and $\mathrm{TI}^{+} @ M M-1$ (bottom spectra) complexes recorded in $\mathrm{LiOH} / \mathrm{H}_{2} \mathrm{O}(0.1 \mathrm{M})$ at $293 \mathrm{~K}$ as a function of the amount of cesium hydroxide or thallium acetate added into the solution ( 0 eq, $0.25 \mathrm{eq}, 0.5 \mathrm{eq}, 0.75 \mathrm{eq}$ and $1.0 \mathrm{eq}$ ). ECD spectra for higher $\mathrm{Cs}^{+}$or $\mathrm{TI}^{+}$concentrations are identical to that recorded for 1 equivalent of $\mathrm{Cs}^{+}$ or $\mathrm{TI}^{+}$.

A modification of the experimental conditions also produces important changes in the ECD spectra of the $M M-1$ derivative. For instance, the presence of a competitor $\left(\mathrm{CHCl}_{3}\right)$ present inside the cavity of $M M-1$ significantly affects the overall ECD spectrum of compound $M M-1$. The replacement of the chloroform molecule by the $\mathrm{Cs}^{+}$or the $\mathrm{Tl}^{+}$cations has a dramatic effect on the global shape of the ECD spectrum of $M M-1$, especially for the ECD bands of the allowed ${ }^{1} B_{b}$ transition located at low wavelength (close to $220 \mathrm{~nm}$ ). Indeed, a strong decrease in intensity is observed upon addition of $\mathrm{Cs}^{+}$or $\mathrm{Tl}^{+}$ cations into the solution (Figure S18 in the Supporting Information). The presence of multiple isosbestic points indicates that both the $\mathrm{Cs}^{+} @ M M-1$ and $\mathrm{TI}^{+} @ M M-1$ complexes are efficiently formed and that these two cations can successfully expel the $\mathrm{CHCl}_{3}$ molecule from the inner cavity of the host. It is noteworthy that a change of the concentration of the $\mathrm{LiOH} / \mathrm{H}_{2} \mathrm{O}$ solution produces similar effects (Figure $\mathrm{S} 19$ in the Supporting Information). For instance, higher $\mathrm{LiOH} / \mathrm{H}_{2} \mathrm{O}$ concentration $(1 \mathrm{M})$ solution gives rise to ECD spectra similar to those recorded for the $\mathrm{CHCl}_{3} @ M M-1$ complex. The addition of $\mathrm{CsOH} / \mathrm{H}_{2} \mathrm{O}$ or $\mathrm{TIOAc} / \mathrm{H}_{2} \mathrm{O}$ into this solution strongly affects the ECD spectra of $M M-1$. In all cases, it is important to note that the ECD spectra remain unchanged when more than one equivalent of $\mathrm{Cs}^{+}$or $\mathrm{Tl}^{+}$are added into the solution. Finally, the replacement of $\mathrm{LiOH} / \mathrm{H}_{2} \mathrm{O}$ by a $\mathrm{KOH} / \mathrm{H}_{2} \mathrm{O}$ solution reveals two different behaviors in the ECD spectra of $M M-1$ upon addition of $\mathrm{Cs}^{+}$or $\mathrm{TI}^{+}$cations. In the presence of cesium hydroxide solution, very small modifications of the ECD spectra of $M M-1$ are observed, whereas the spectral changes are more pronounced when a thallium acetate solution was added (Figure S20 in the Supporting Information).
Vibrational Circular Dichroism Spectroscopy. The VCD spectrum of empty $P P-1$ is compared in Figure 3 with the VCD spectra of $\mathrm{CDCl}_{3} @ P P-1$ and $\mathrm{Cs}^{+} @ P P-1$ complexes recorded in $\mathrm{NaOD} / \mathrm{D}_{2} \mathrm{O}(0.21 \mathrm{M})$ solution. Important spectral modifications occur upon complexation of $\mathrm{CDCl}_{3}$ and $\mathrm{Cs}^{+}$, as already observed for compound $3^{[1]]}$ Indeed, the intensity of the band at $1495 \mathrm{~cm}^{-1}$ increases for the $\mathrm{CDCl}_{3} @ P P-1$ complex, whereas this band presents a bisignate pattern for the $\mathrm{Cs}^{+} @ P P-1$ complex. On the other hand, the intensity of the band at $1600 \mathrm{~cm}^{-1}$ strongly increases for the $\mathrm{Cs}^{+} @ P P-1$ complex. These spectral changes, as well as those observed in the $1450-1250 \mathrm{~cm}^{-1}$ region, which correspond to coupled modes involving wagging and twisting vibrations of the $\mathrm{CH}_{2}$ groups (chains and caps), may be interpreted as a modification of the conformation of the linkers of host 1 . Thus, the presence of $\mathrm{CDCl}_{3}$ inside the cavity of 1 favors the trans conformation of the ethylenedioxy linkers whereas the presence of $\mathrm{Cs}^{+}$cations favors the gauche conformations of the linkers in order to maximize the host-guest interactions.

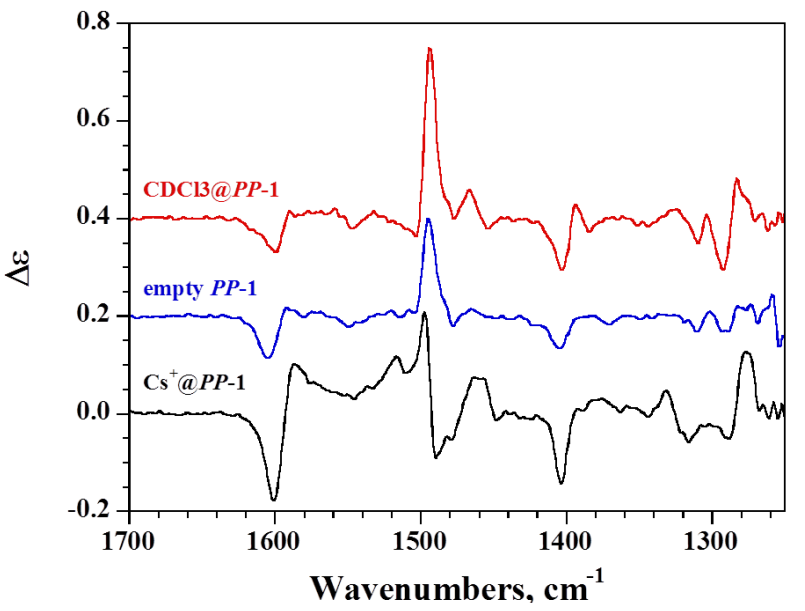

Figure 3. VCD spectra of empty $P P-1$ as well as $\mathrm{CDCl}_{3} @ P P-1$ and $\mathrm{Cs}^{+} @ P P-1$ complexes recorded at $293 \mathrm{~K}$ in $\mathrm{NaOD} / \mathrm{D}_{2} \mathrm{O}$ solution $(0.21 \mathrm{M})$. The concentration of host 1 was $0.030 \mathrm{M}$.

DFT Calculations. Quantum chemistry calculations have been performed to understand the nature of the various interactions that can exist between the host and the cations. These calculations are also expected to be useful to understand the origin of the large NMR chemical shift observed for the $\mathrm{Cs}^{+} @ 1$ and the $\mathrm{TI}^{+} @ 1$ complexes. Thus, we have carried out orbital, topological and energy decomposition analyses (EDA) along with the calculation of chemical shift for the $\mathrm{Cs}^{+} @ 1$ and the $\mathrm{TI}^{+} @ 1$ complexes with quantum chemistry methods. ${ }^{[8,9]}$ Computational details are provided in the Supporting Information. The optimized geometry of the complexes is rather similar for alkali metals $\left(\mathrm{K}^{+}, \mathrm{Rb}^{+}, \mathrm{Cs}^{+}\right)$and for the heavier $\mathrm{TI}^{+}$cation, as shown in Figure 4. However, the position of the $\mathrm{Tl}^{+}$cation within the cryptophane cage differs from that of $\mathrm{Cs}^{+}$, revealing a modification of the interaction between the $\mathrm{TI}^{+}$cation and the cage.

The nature of the bonding interactions between the metal and the host has been first investigated with an energy partitioning of the total interaction energy into components familiar to chemists, namely electrostatic, Pauli repulsion and orbital mixing. 


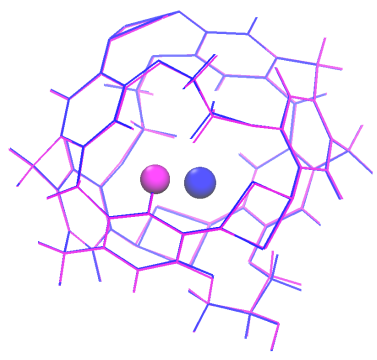

Figure 4. Optimized geometry of the $\mathrm{Cs}^{+} @ 1$ (blue) and $\mathrm{TI}^{+} @ 1$ (magenta) complexes.

It is important to note that all of the terms assignable to the bond (polarization, charge-transfer, etc.) are grouped into a single orbital interaction term. The results are reported in Figure 5 .

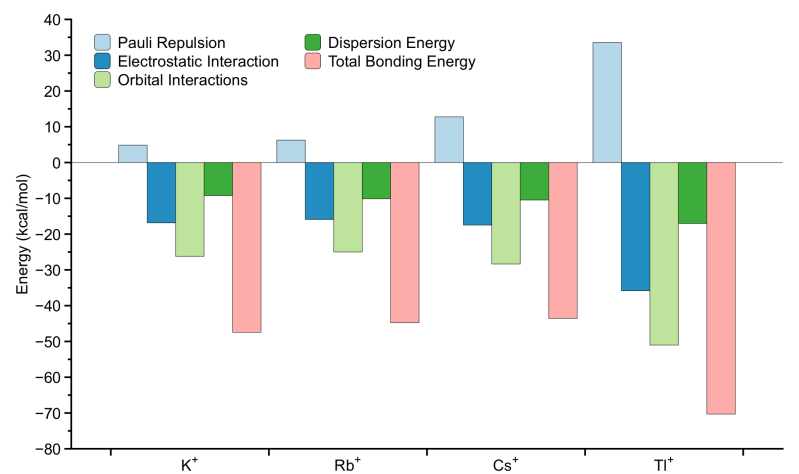

Figure 5. DFT PBE/TZ2P bonding energy analysis with respect to the $\mathrm{M}^{+}$and cryptophane fragments

The $\mathrm{M}^{+} @ 1$ total bonding energy is a negative value indicating stabilization during encapsulation of the cation, which originates mainly in attractive electrostatic $(\sim 32 \%$ of the total attractive interactions) and orbital interactions $(\sim 50 \%$ of the total attractive interactions). The dispersion forces are a non-negligible component of the interaction $(\sim 18 \%$ of the total attractive interactions). The spatial regions in which the non-covalent interactions (electrostatic, dispersion) are taking place are visualized in Figure 6.

The total bonding energy is much more negative for the $\mathrm{Tl}^{+}$ complex than for the $\mathrm{Cs}^{+}$complex. The Voronoi Deformation Density (VDD) analysis reveals if charge flows away or toward the space around a certain nucleus upon the formation of the complex from its fragments. ${ }^{[10]}$ Upon encapsulation of the alkali metals the VDD analysis indicates that no charge transfer occurs between the cage and the cation. In contrast, in the case of the thallium cation, 0.2 electrons $(0.25$ electrons from natural bond orbital (NBO) analysis) are transferred from the cage to the $6 \mathrm{p}$ orbital of the $\mathrm{Tl}^{+}$cation. $^{[1]}$

The $6 d(T I)$ orbital mixes the $2 p(C)$ orbital of the phenyl ring (symmetrized fragment orbital analysis). ${ }^{[9]}$ The calculation reveals that the $\mathrm{TI}^{+} @ 1$ complex is also stabilized at lower energy (See Figure 1a in the computational details in the Supporting Information) by the mixing of the $6 s(\mathrm{TI})$ orbital with the $2 p(\mathrm{C})$ orbital of the aromatic ring. In the alkali metal complexes, the $5 p(M)$ orbital mixes with the $2 p(C)$ orbital of all cages (See Figure $1 \mathrm{~b}$ in the computational details in the Supporting Information).

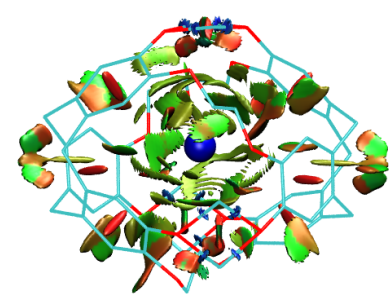

a)

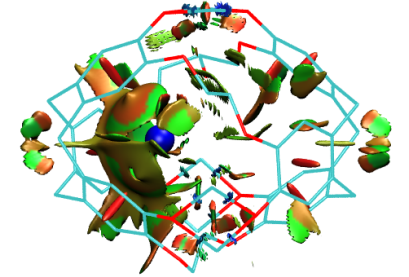

b)
Figure 6. Spatial regions of non-covalent interaction. The non-covalent interaction regions appear in green and light brown for $\mathrm{Cs}^{+}$(a) and $\mathrm{Tl}^{+}$(b). Hydrogen atoms are removed for clarity. The cations are in blue color.

From this analysis, it is clear that the phenyl ring- $\mathrm{TI}^{+}$interaction is predominant inside the cryptophane cage. The $\mathrm{TI}^{+} @ 1$ complex is stabilized by orbital interactions and by cation- $\pi$ interactions. In the alkali metal series, cation- $\pi$ interactions cannot be clearly identified.

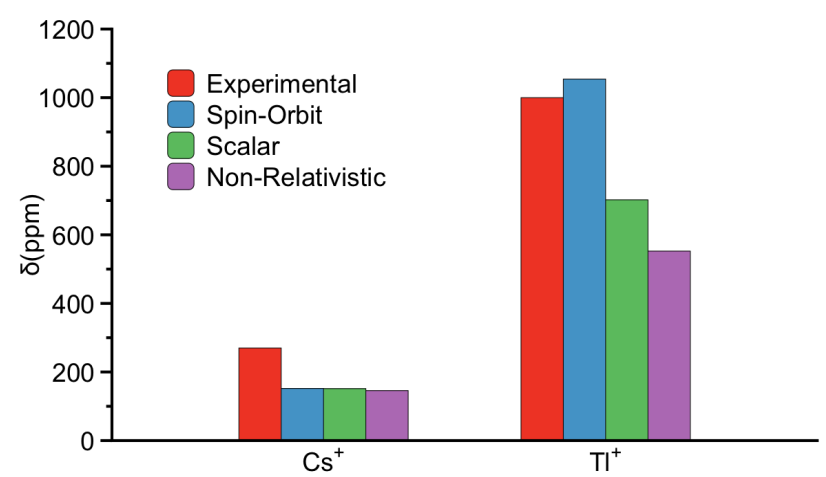

Figure 7. Calculated chemical shifts using a secondary reference (See computational details in the Supporting Information).

These different interaction patterns, as revealed by the ECD spectra, have a consequence on the magnetic properties of the metal ions. The $\mathrm{M}^{+}$isotropic shielding was calculated through the DFT/GIAO shielding tensor. The results are reported in Figure 7 for $\mathrm{Cs}^{+}$and $\mathrm{Tl}^{+}$. As shown in Figure 7, it is critical to take into account explicitly all the relativistic contributions (scalar and spin-orbit) to the nuclear shielding for TI element. Upon complexation, the electronic effects (phenyl ring $\pi$ electrons and cation-cryptophane orbital interaction) increase the electron density at the nucleus. For the $\mathrm{TI}^{+}$complex, this effect is large, shifting the NMR signal to high field with a huge chemical shift variation with respect to that experienced by the alkali metal cations.

\section{Discussion}

Comparison of the binding properties of 1 with cryptophane congeners 2 - 5. ITC experiments performed on the $\mathrm{Cs}^{+} @(\mathrm{rac})$ 1 and the $\mathrm{TI}^{+} @(\mathrm{rac})-1$ complexes reveal a very high affinity of host 1 for the cesium and thallium cations. This cage shows the highest affinity for the $\mathrm{TI}^{+}$cation. The affinity of 1 for $\mathrm{Cs}^{+}$is about ten times smaller than the affinity measured for $\mathrm{TI}^{+}$. In addition, the $\mathrm{Rb}^{+}$and $\mathrm{K}^{+}$cations are much less recognized by the host since the affinity for these two cations is about one thousand and one million times smaller, respectively, than the binding constant measured for the $\mathrm{Cs}^{+}$cation. The same trend was 
previously observed with cryptophanes 2 - 5. ${ }^{[1,, 1 f, 6]}$ Altogether our results show that a clear relationship can be established between the magnitude of the binding constant and the polarizability of the $\mathrm{M}^{+}$cation $\left(\mathrm{TI}^{+}>\mathrm{Cs}^{+}>\mathrm{Rb}^{+}>\mathrm{K}^{+}>>\mathrm{Na}^{+}, \mathrm{Li}^{+}\right)$.

The affinity of 1 for the $\mathrm{Cs}^{+}$and $\mathrm{Tl}^{+}$cations lies in the same range than the binding constant measured for compounds 2 and $4^{[1, e, 6]}$ These compounds also possess six phenol groups attached on the benzene rings but their cavity size is different. Compounds $\mathbf{1}$ and $\mathbf{4}$ have the closest structures since they differ only by the presence of a secondary alcohol function in 1 . Thus, upon complexation of $\mathrm{Cs}^{+}$or $\mathrm{Tl}^{+}$it is not surprising to observe comparable binding constants between these two compounds. The similarity in magnitude of the binding constants suggests that the alcohol group present in $\mathbf{1}$ does not play any crucial role in the stabilization of the complex. This is probably because the $\mathrm{OH}$ function points outside the cavity and cannot establish specific interactions with the metal cation present within the cavity. A minimized structure of the host obtained by DFT supports this assumption.

Comparison of the ECD spectra of 1 with compounds 2 and 3 reveals the same evolution of the ECD spectra in the presence of metal cations. ECD spectroscopy was found to be very sensitive to the conformational changes of water-soluble cryptophanes upon encapsulation of guest molecules or cations. ${ }^{[1]}$ The $\mathrm{Cs}^{+}$or $\mathrm{TI}^{+}$encapsulation induces large spectral modifications, which are the consequence of the conformational rearrangements of the linkers. These conformational rearrangements allow the cage to change its cavity size in order to maximize its interactions with the metal cations. It is noteworthy that a higher concentration of $\mathrm{Cs}^{+}$or $\mathrm{TI}^{+}$cations (more than 1 equivalent) does not induce further spectral changes, suggesting that host-guest interactions are solely responsible of the observed effect. Such spectral changes have already been observed with compounds 2 and $3,^{[1,11]}$ but it is interesting to notice that in the case of 1 these effects are not amplified, even though host 1 is potentially subject to larger conformational changes. Indeed, the propylenedioxy linker, present in the structure of $\mathbf{1}$, is certainly more favorable to conformational changes than ethylenedioxy linkers (compounds 2 and 3 ).

The ECD experiments performed in the presence of a competitor $\left(\mathrm{CHCl}_{3}\right)$ or in $\mathrm{KOH} / \mathrm{H}_{2} \mathrm{O}$ solution give new insight to interpret the behavior of 1 in the presence of metal cations. For instance, important similarities are observed between the ECD spectra of the $\mathrm{CHCl}_{3} @ M M-1$ complex $\left(\mathrm{LiOH} / \mathrm{H}_{2} \mathrm{O}, 0.1 \mathrm{M}\right)$ and the spectrum recorded at higher $\mathrm{LiOH} / \mathrm{H}_{2} \mathrm{O}(1 \mathrm{M})$ concentration. This indicates that the cage adopts a similar conformation in solution. The chloroform molecule possesses a large molecular volume $\left(\mathrm{V}_{\mathrm{vdw}}=72 \AA^{3}\right)$ that forces the cage to enlarge its cavity (increasing the proportion of trans conformation of the linkers). Interestingly, increasing the concentration of the basic solution seems to produce a similar effect. Nevertheless, high concentrations of $\mathrm{LiOH}$ are not the most favorable conditions to observe efficient complexation of metal cations. However, the interactions between cage 1 and $\mathrm{Cs}^{+}$or $\mathrm{Tl}^{+}$seem to be strong enough to provoke a conformational change that reduces the cavity size (the complexation of $\mathrm{Cs}^{+}$or $\mathrm{Tl}^{+}$cations favors the proportion of gauche conformation). An opposite effect takes place when the experiments are performed in $\mathrm{KOH}$ solution. We have reported that $\mathrm{K}^{+}$cations bind moderately to cage 1 . Thus, $\mathrm{K}^{+}$acts as a competitor for $\mathrm{Cs}^{+}$or $\mathrm{Tl}^{+}$, resulting in a decrease of the observed binding constants by two orders of magnitude. The encapsulation of the $\mathrm{K}^{+}$cation also results in a pre-organization of the host molecule leading to moderate chiroptical changes upon $\mathrm{Cs}^{+}$and $\mathrm{TI}^{+}$encapsulation. Indeed, these cations have similar volumes and the replacement of $\mathrm{K}^{+}\left(\mathrm{V}_{\mathrm{vdw}}=11 \AA^{3}\right)$ by $\mathrm{Cs}^{+}$ $\left(V_{v d w}=20 \AA^{3}\right)$ or $\mathrm{TI}^{+}\left(V_{v d w}=14 \AA^{3}\right)$ is not expected to modify significantly the cavity size of the host.
The ECD experiments also reveal a clear difference between the ECD spectra of the $\mathrm{Cs}^{+} @ M M-1$ and $\mathrm{TI}^{+} @ M M-1$ complexes. Indeed, a bathochromic shift of the ECD bands of the ${ }^{1} L_{b}$ transition $(280-320 \mathrm{~nm})$ is observed for the $\mathrm{TI}^{+} @ M M-1$ complex. This effect has been previously observed for compounds 2-5 in the presence of $\mathrm{TI}^{+}{ }^{[1 f, 6]}$ This seems to be an indication that $\mathrm{TI}^{+}$interact differently with the cages. DFT calculations support this assumption (see below).

Understanding the nature of the interaction between the metallic cations and the cage. For the first time, DFT calculations have been performed comparatively for the $\mathrm{Cs}^{+} @ 1$ and $\mathrm{TI}^{+} @ 1$ complexes. A theoretical approach that consists to decompose the total binding energy into different contributions (electrostatic, Pauli interaction, orbital interaction and dispersion energy) is very useful to understand the nature of the interactions that takes place between the cations and host 1 . These DFT calculations confirm that the $\mathrm{Tl}^{+}$cation interacts more strongly with the cage than the $\mathrm{Cs}^{+}$cation. In the case of the $\mathrm{Tl}^{+}$cation, the calculations reveal that the Pauli repulsion term is strongly positive for the $\mathrm{TI}^{+}$and contributes significantly to the destabilization of the complex. However, this term is largely compensated by the strongly negative electrostatic and orbital interaction terms with a non-negligible charge transfer between $\mathrm{Tl}^{+}$and the cage. These terms dominate the host-guest interactions, and the summation over the different contributions leads to a large negative total binding energy $(\Delta E=-70 \mathrm{kcal} / \mathrm{mol})$, which is characteristic of the formation of a very stable complex. In the case of the $\mathrm{Cs}^{+}$cation, the total binding energy is significantly lower $(\Delta E=-40 \mathrm{kcal} / \mathrm{mol})$. Indeed, even though the positive contribution of the Pauli repulsion term is much less important than for $\mathrm{Tl}^{+}$, the two electrostatic and orbital interaction terms are decreased by a factor 2 in magnitude leading to a weaker total binding energy.

These results are consistent with the ECD measurements that suggest a stronger interaction between the cage and the $\mathrm{TI}^{+}$ cation (bathochromic effect of the ${ }^{1} L_{b}$ transition). In contrast, the calculations reveal a similar behavior for the interactions of the $\mathrm{Cs}^{+}$and $\mathrm{Rb}^{+}$cations with the cage. This is also consistent with the ECD measurements that show similar spectra for these two species (data not shown). Thus, it can be claimed that the ECD spectra are not only characteristic of the conformational changes of the host but they are also characteristic of the nature of the interaction that takes place between the metal cations and the two cyclotribenzylene units that constitutes the cryptophane skeleton.

A direct comparison between DFT binding energy (from EDA) and binding constants measured by titration experiments is not appropriate. Indeed, EDA is a very powerful method for a qualitative and quantitative analysis of the chemical bond. This method reports the instantaneous interaction energy between two fragments (the cage and the cation) in the molecular system. In this calculation, neither the full thermodynamics effects nor the solvation effects in reference to experiments are included. Hard cations such as $\mathrm{K}^{+}$and $\mathrm{Rb}^{+}$are probably more solvated that soft cation such as $\mathrm{Cs}^{+}$. Consequently, solvation of the cationic species is expected to decrease the electrostatic interaction term more rapidly in the case of the $\mathrm{K}^{+}$and $\mathrm{Rb}^{+}$ cations than in the case of the $\mathrm{Cs}^{+}$cation. The solvation of the cage must also be taken into account in our case. It is noteworthy that the presence of water molecules inside the cavity of the host is an important issue to understand the binding properties of the cryptophane derivatives in aqueous solution, especially when cationic species are present within the cavity. The presence of water molecules inside the cavity of cryptophane hosts has already been evidenced both experimentally (X-ray crystallography) and theoretically. ${ }^{[12,13]}$ The demonstration of the presence of a water molecule inside the 
cavity and its role in the binding properties of charged species is very difficult to tackle from an experimental point of view. Experimental procedures based on ITC experiments have been recently proposed to address this problem. ${ }^{[14]}$ For instance, Eggers and co-workers have suggested treating water molecules as a co-reactant in order to have access to the global desolvation free energy term. This approach is interesting but also time demanding and it is out of the scope of this article. From a theoretical point of view, an implicit solvation model cannot take into account these phenomena. An explicit solvation model including in the case of the cryptophane cage inner water molecules and several outer solvation shells is mandatory, leading to time demanding calculations.

${ }^{133} \mathrm{Cs}$ and ${ }^{205} \mathrm{TI}$ NMR spectra of the complexes. ${ }^{133} \mathrm{Cs}$ and ${ }^{205} \mathrm{TI}$ nuclei are known to be very sensitive to their surrounding environment. In the past, we have reported that both nuclei give rise to very important chemical shift differences between the metallic cation dissolved in the bulk and the cation present within the cavity of the cryptophane hosts. ${ }^{[1,11]}$ These frequency differences were found more important for the $\mathrm{TI}^{+}$cation than for the $\mathrm{Cs}^{+}$cation. These findings are still observed with compound 1 , and can be the consequence of several parameters. As mentioned above $\mathrm{TI}^{+}$interacts more strongly with the cage and its polarizability is about twice that of the $\mathrm{Cs}^{+}$cation. Consequently, a small change in the cryptophane structure can induce very large chemical shift differences for these two nuclei. For instance, a comparison of the ${ }^{133} \mathrm{Cs}$ and ${ }^{205} \mathrm{TI}$ NMR spectra of compounds 1 and 4 reveals the high sensitivity of these two nuclei for their immediate environment. At room temperature, a chemical shift difference, $\Delta \delta$, of $10-15 \mathrm{ppm}$ is observed between the two $\mathrm{Cs}^{+} @(\mathrm{rac})-\mathbf{1}$ and the $\mathrm{Cs}^{+} @(\mathrm{rac})-\mathbf{4}$ complexes. This difference is much larger in the case of the ${ }^{205} \mathrm{TI}$ nuclei, since $\Delta \delta=110 \mathrm{ppm}$ at $335 \mathrm{~K}$ (Figure 1). ${ }^{[15]}$

It is noteworthy that the high sensitivity of the ${ }^{205} \mathrm{TI}$ nucleus with its immediate environment also explains the large chemical shift differences between $\mathrm{TI}^{+}$in the bulk and the $\mathrm{Tl}^{+} @(\mathrm{rac})-1$ complex. This chemical shift reaches a value $\Delta \delta \sim 1030 \mathrm{ppm}$ at $335 \mathrm{~K}$. DFT calculations are very helpful and informative to interpret such high chemical shift difference. For instance, in the case of ${ }^{205} \mathrm{TI}$, these calculations show that relativistic contributions such that spin-orbit coupling is a very important parameter, which has to be taken into account to predict correctly the chemical shift of the $\mathrm{TI}^{+} @ 1$ complex. In the case of the $\mathrm{Cs}^{+} @ 1$ complex, the contribution of the spin-orbit coupling is less important and this contribution can be neglected.

The temperature effect observed in the case of the Cs ${ }^{+} @ 1$ complex is intriguing and counter-intuitive. It is noteworthy that a similar effect also occurs with cryptophanes 2, $\mathbf{3}$ and 4, which show high affinity for $\mathrm{Cs}^{+}$. In contrast, an opposite effect is observed with compound $\mathbf{5}$ that exhibits the lowest association constant with $\mathrm{Cs}^{+}{ }^{[6]}$ We have also noticed that the broadening of the $\mathrm{Cs}^{+}$NMR signal observed at lower temperature seems related to the symmetry of the host. Thus, the higher the symmetry of the host the sharper the ${ }^{133} \mathrm{Cs}$ NMR signal at low temperature. For instance, at $278 \mathrm{~K}$ the $\mathrm{Cs}^{+} \mathrm{NMR}$ spectrum of compound $1\left(\mathrm{C}_{1}\right.$-symmetry) shows a signal larger than that of compound 2 ( $\mathrm{D}_{3}$-symmetry). DFT calculations reveal that coulombic interactions between $\mathrm{Cs}^{+}$and the phenolate group are important. Considering that the $\mathrm{Cs}^{+}$cation is small with respect to the volume of the inner cavity of the hosts, we can thus assume that $\mathrm{Cs}^{+}$interacts with the different $\mathrm{OH}$ groups of the host. Consequently, it explores different regions of the cavity leading to a broadening of the signal at lower temperature. A decrease of the symmetry of the host results in a larger $\mathrm{Cs}^{+}$ NMR signal at low temperature. Increasing the temperature results in a mean value of this ${ }^{133} \mathrm{Cs}$ NMR signal. This assumption does not take into account important characteristics of the cesium nucleus ( ${ }^{133} \mathrm{Cs}$ has a weak quadrupolar moment) and the possible conformation changes of the host that could take place with a change of the temperature. However, these considerations are not consistent with the fact that compound $\mathbf{5}$ shows an opposite behavior. In addition, it must be mentioned that a similar temperature effect seems to occur with the ${ }^{205} \mathrm{TI}$ (no quadrupolar moment). Additional work is needed to fully address and understand this surprising effect.

\section{Conclusions}

We have described the synthesis of the two enantiomers $M M-1$ and PP-1 from enantiopure cryptophanes $M M-6$ and PP-6, respectively. The two enantiomers $M M-6$ and $P P-6$ have been isolated by semi-preparative HPLC on chiral stationary phase. Then, subsequent reactions afforded the desired $M M-1$ and $P P$ 1 derivatives. We have also studied the binding properties of the water-soluble cryptophane 1 in basic aqueous solution in the presence of metallic cations $\left(\mathrm{M}^{+}=\mathrm{Rb}^{+}, \mathrm{Cs}^{+}, \mathrm{Tl}^{+}\right)$. The titration experiments (ITC) show a very high affinity of 1 for the $\mathrm{Cs}^{+}$and $\mathrm{Tl}^{+}$cations under a large range of experimental conditions. For instance, a binding constant as high as $K=1.0 \times 10^{10} \mathrm{M}^{-1}$ has been measured for $\mathrm{TI}^{+} @ 1$ complex in $\mathrm{LiOH} / \mathrm{H}_{2} \mathrm{O}(0.1 \mathrm{M})$. Chiroptical techniques (ECD and VCD) have been used to investigate the conformational changes that take place during the encapsulation process. The formation of the $\mathrm{Cs}^{+} @(\mathrm{rac})-1$ and $\mathrm{TI}^{+} @($ rac $)-1$ complexes has been also studied via ${ }^{133} \mathrm{Cs}$ and ${ }^{205}$ TI NMR spectroscopy, where the low-field signals with respect to the free cations in solution is used to unambiguously detect these two complexes even at high temperature (335 K).

On the other hand, DFT calculations have shown to be a valuable tool to understand the nature of the interaction existing between the cage and the different cations. These calculations suggest that the $\mathrm{TI}^{+}$cation interacts differently with the cage than the other alkali cations studied in this article $\left(\mathrm{M}^{+}=\mathrm{K}^{+}, \mathrm{Rb}^{+}, \mathrm{Cs}^{+}\right)$. For instance, thanks to an energy decomposition analysis, these calculations show the predominance of the electrostatic and orbital interactions in the stabilization of the $\mathrm{TI}^{+} @ 1$ complex. The theoretical investigation of the electronic structure and bonding revealed cation- $\pi$ interactions in the $\mathrm{TI}^{+} @ 1$ complex. In the alkali metal series, $\pi$-cation interactions cannot be clearly identified. In addition, this theoretical work shows that the large chemical shift observed in the case of the $\mathrm{Tl}^{+} @ 1$ complex ( $\left.\Delta \delta \sim 1000 \mathrm{ppm}\right)$ can be only explain by including relativistic contribution such as spinorbit coupling interactions and a non-negligible charge transfer between $\mathrm{TI}^{+}$and the cage.

The originality in the structure of host 1 lies in the presence of a hydroxyl function that can be used for subsequent reactions. Since the secondary alcohol does not directly participate to the stabilization of the $\mathrm{M}^{+} @ 1$ complexes, it can be used at a later stage for grafting an organic spacer linked to a solid support. A synthetic work is under way to graft these molecules onto solid supports (superparamagnetic nanoparticles) with the objective of increasing the extraction yield of cesium and thallium cations from aqueous solutions. ${ }^{[16]}$

\section{Supporting Information Summary}

Experimental section, HPLC and ECD spectra of MM-6 and PP6, ${ }^{1} \mathrm{H}$ and ${ }^{13} \mathrm{C}$ NMR spectra of $M M-1$ and $P P-1,{ }^{1} \mathrm{H}$ and ${ }^{13} \mathrm{C}$ NMR spectra of $M M-7$ and $P P-7$, isothermal titration calorimetric (ITC) experiments and thermodynamic parameters of the $\mathrm{M}^{+} @ 1$ complexes $\left(\mathrm{M}^{+}=\mathrm{Cs}^{+}\right.$and $\left.\mathrm{TI}^{+}\right),{ }^{133} \mathrm{Cs}$ NMR spectra of the 
${ }^{133} \mathrm{Cs@1} \mathrm{complex} \mathrm{at} \mathrm{variable} \mathrm{temperature,} \mathrm{ECD} \mathrm{spectra} \mathrm{of} \mathrm{the}$ $\mathrm{Cs}^{+} @ 1$ and $\mathrm{TI}^{+} @ 1$ complexes, computational details.

\section{Acknowledgements}

The authors are indebted to the CNRS (Chemistry Department) and to Région Aquitaine for financial support in VCD equipments. The GDR 3712 Chirafun is acknowledged for allowing a collaborative network between some partners of this project.

\section{Conflict of Interest}

The authors declare no conflict of interest.

Keywords: Calorimetry $\bullet$ Chirality $\bullet$ Circular Dichroism $・$ DFT Calculations $\bullet$ Molecular Recognition

[1] a) A. Bouchet, T. Brotin, D. Cavagnat, T. Buffeteau, Chem. -Eur. J. 2010, 16, 4507; b) A. Bouchet, T. Brotin, M. Linares, H. Agren, D. Cavagnat, T. Buffeteau, J. Org. Chem. 2011, 76, 1372; c) A. Bouchet, T. Brotin, M. Linares, D. Cavagnat, T. Buffeteau, J. Org. Chem. 2011, 76, 7816; d) A. Bouchet, T. Brotin, M. Linares, H. Ågren, D. Cavagnat, T. Buffeteau, J. Org. Chem. 2011, 76, 4178; e) T. Brotin, R. Montserret, A. Bouchet, D. Cavagnat, M. Linares, T. Buffeteau, J. Org. Chem. 2012, 77, 1198; f) T. Brotin, D. Cavagnat, P. Berthault, R. Montserret, T. Buffeteau, J. Phys. Chem. B 2012 , 116, 10905.

[2] L. L. Chapellet, J. R. Cochrane, E. Mari, C. Boutin, P. Berthault, T. Brotin, J. Org. Chem. 2015, 80, 6143.

[3] E. Vedejs, P. L. Fuchs, J. Am. Chem. Soc. 1973, 95, 822.

[4] R. E. Ireland, D. M. Walba, Org. Synth. 1977, 56, 44.

[5] G. Huber, T. Brotin, L. Dubois, H. Desvaux, J. P. Dutasta, P. Berthault, J. Am. Chem. Soc. 2006, 128, 6239

[6] T. Brotin, S. Goncalves, P. Berthault, D. Cavagnat, T. Buffeteau, J. Phys. Chem. B 2013, 117, 12593.

[7] J. F. Hinton, Bull. Magn. Reson. 1992, 13, 90.

[8] F. M. Bickelhaupt, E. J. Baerends In Reviews of Computational Chemistry, D. B. Boyd, K. B. Lipkowitz, Wiley-VCH: New York, 2000, P. 1, Vol. 15.

[9] [G. te Velde, F. M. Bickelhaupt, E. J. Baerends, C. Fonseca Guerra, S. J. A. van Gisbergen, J. G. Snijders, T. Ziegler, J. Comput. Chem., 2001, 22 931.

[10] F. M. Bickelhaupt, N. J. R. van Eikema Hommes, C. Fonseca Guerra, E. J. Baerends, Organometallics, 1996, 15, 2923.

[11] A. E. Reed, R. B. Weinstock, F. Weinhold, J. Chem. Phys. 1985, 83

[12] O. Taratula, P. A. Hill, N. S. Khan, P. J. Carroll, I. J. Dmochowski, Nat. Comm. 2010, 1.

[13] L. Gao, W. Liu, O-S. Lee, I. J. Dmochowski, J. G. Saven, Chem. Sci. 2015, 6, 7238 .

[14] B. M. Castellano, D. K. Eggers, J. Phys. Chem. B 2013, 117, 8180

[15] This temperature has been chosen because the ${ }^{205}$ TI NMR spectra are not well resolved at room temperature.

[16] E. Siurdyban, T. Brotin, D. Talaga, K. Heuzé, L. Vellutini, T. Buffeteau, J. Phys. Chem. C 2016, 120, 6583. 


\section{Supporting Information}

\section{Table of contents}

Figure S1: Chromatograms (Chiralpak ID, $250 \times 4.6 \mathrm{~mm}$, $\mathrm{EtOH} / \mathrm{CH}_{2} \mathrm{Cl}_{2}: 20 / 80,1 \mathrm{~mL} / \mathrm{min}$ ) of the collected anti-1 enantiomers after preparative separation on Chiralpak ID $\left(250 \times 10 \mathrm{~mm}, \mathrm{EtOH} / \mathrm{CH}_{2} \mathrm{Cl}_{2}\right.$ : $20 / 80,5 \mathrm{~mL} / \mathrm{min}$ ) by 120 injections of $4.4 \mathrm{mg}$ of racemate. Detection by UV-vis spectroscopy at 254 $\mathrm{nm}$ (black chromatograms) and CD spectroscopy at $254 \mathrm{~nm}$ (red chromatograms).

Figure S2: $E C D$ spectra of compound $M M-6$ and $P P-6$ recorded in $\mathrm{CHCl}_{3}$ (a: top spectrum; $\mathrm{c}=1.12$ $\left.10^{-4} \mathrm{M}-9.0410^{-5} \mathrm{M}\right)$ and in $\mathrm{CH}_{2} \mathrm{Cl}_{2}$ (b: bottom spectrum; $\mathrm{c}=9.4110^{-5} \mathrm{M}-8.8810^{-5} \mathrm{M}$ ). Polarimetric measurements of compounds $M M-6$ and $P P-6$ recorded at $25^{\circ} \mathrm{C}$ in $\mathrm{CHCl}_{3}$.

Figure S3: ${ }^{1} \mathrm{H}$ NMR spectrum $(300 \mathrm{MHz})$ of the enantiomer MM-1 recorded in DMSO- $d_{6}$ at $298 \mathrm{~K}$.

Figure S4: ${ }^{13} \mathrm{C}$ NMR spectrum $(75.47 \mathrm{MHz})$ of the enantiomer MM-1 recorded in DMSO- $d_{6}$ at $298 \mathrm{~K}$.

Figure S5: ${ }^{1} \mathrm{H}$ NMR spectrum $(300 \mathrm{MHz})$ of the enantiomer PP-1 recorded in DMSO- $d_{6}$ at $298 \mathrm{~K}$.

Figure S6: ${ }^{13} \mathrm{C}$ NMR spectrum $(75.47 \mathrm{MHz})$ of the enantiomer $P P-1$ recorded in DMSO- $d_{6}$ at $298 \mathrm{~K}$.

Figure S7: ${ }^{1} \mathrm{H}$ NMR spectrum $(300 \mathrm{MHz}$ ) of the enantiomer PP-7 (non-imploded form) recorded in $\mathrm{CD}_{2} \mathrm{Cl}_{2}$ at $298 \mathrm{~K}$.

Figure S8: ${ }^{1} \mathrm{H}$ NMR spectrum $(300 \mathrm{MHz}$ ) of the enantiomer PP-7 (mainly imploded form) recorded in $\mathrm{CD}_{2} \mathrm{Cl}_{2}$ at $298 \mathrm{~K}$. in insert: comparison of the ${ }^{1} \mathrm{H}$ NMR spectra of the imploded and non-imploded form (aromatic region only).

Figure S9: ${ }^{13} \mathrm{C}$ NMR spectrum $(75.47 \mathrm{MHz})$ of the enantiomer PP-7 (non-imploded form) recorded in $\mathrm{CD}_{2} \mathrm{Cl}_{2}$ at $298 \mathrm{~K}$.

Figure S10: ${ }^{1} \mathrm{H}$ NMR spectrum $\left(300 \mathrm{MHz}\right.$ ) of the enantiomer $M M-7$ recorded in $\mathrm{CD}_{2} \mathrm{Cl}_{2}$ at $298 \mathrm{~K}$. 
Figure S11: ${ }^{13} \mathrm{C}$ NMR spectrum $(75.47 \mathrm{MHz}$ ) of the enantiomer MM-7 (non-imploded form) recorded in $\mathrm{CD}_{2} \mathrm{Cl}_{2}$ at $298 \mathrm{~K}$.

Figure S12: Calorimetric titration of 1 in $\mathrm{LiOH} / \mathrm{H}_{2} \mathrm{O}(0.1 \mathrm{M})$ at $298 \mathrm{~K}$ in presence (or not) of $\mathrm{RbCl}$ (top left), $\mathrm{CsOH}$ (top right) or TIOAc (bottom). The host solution (top left, $\mathrm{c}=99.3 \mu \mathrm{M}$; top right, $\mathrm{c}=26.0$ $\mu \mathrm{M}$; bottom, $\mathrm{c}=30.2 \mu \mathrm{M})$ was placed into the calorimeter cell $(1.4 \mathrm{~mL})$ and 28 successive aliquots (10 $\mu \mathrm{L}$ ) of $\mathrm{RbCl}$ (top left $\mathrm{c}=1.029 \mathrm{mM}$ ), $\mathrm{CsOH}$ (top right, $\mathrm{c}=0.404 \mathrm{mM}$ ) and TIOAc (bottom, $\mathrm{c}=0.406$ $\mathrm{mM}$ ) were added at $3 \mathrm{~min}$ intervals. The concentration of $\mathrm{RbCl}$ was: top right, $\mathrm{c}=0.302 \mathrm{mM}$; bottom, $\mathrm{c}$ $=0.598 \mathrm{mM}$ (competition experiments).

Figure S13: Calorimetric titration of 1 in $\mathrm{NaOH} / \mathrm{H}_{2} \mathrm{O}(0.1 \mathrm{M})$ at $298 \mathrm{~K}$ in presence (or not) of $\mathrm{RbCl}$ (top left), $\mathrm{CsOH}$ (top right) or TIOAc (bottom). The host solution (top left, $\mathrm{c}=100 \mu \mathrm{M}$; top right, $\mathrm{c}=29.9 \mu \mathrm{M}$; bottom, $c=30.2 \mu \mathrm{M})$ was placed into the calorimeter cell $(1.4 \mathrm{~mL})$ and 28 successive aliquots $(10 \mu \mathrm{L})$ of $\mathrm{RbCl}$ (top left $\mathrm{c}=1.0 \mathrm{mM}$ ), $\mathrm{CsOH}$ (top right, $\mathrm{c}=0.398 \mathrm{mM}$ ) and TIOAc (bottom, $\mathrm{c}=0.387 \mathrm{mM}$ ) were added at 3 min intervals. The concentration of $\mathrm{RbCl}$ was: top right, $\mathrm{c}=0.500 \mathrm{mM}$; bottom, $\mathrm{c}=0.911$ $\mathrm{mM}$ (competition experiments).

Figure S14: Calorimetric titration of 1 in $\mathrm{KOH} / \mathrm{H}_{2} \mathrm{O}(0.1 \mathrm{M})$ at $298 \mathrm{~K}$ in presence $\mathrm{CsOH}$ (top) or $\mathrm{TIOAc}$ (bottom). The host solution (top, $\mathrm{c}=40.2 \mu \mathrm{M}$; bottom, $\mathrm{c}=75.4 \mu \mathrm{M}$ ) was placed into the calorimeter cell $(1.4 \mathrm{~mL})$ and 28 successive aliquots $(10 \mu \mathrm{L})$ of $\mathrm{CsOH}$ (top, $\mathrm{c}=0.400 \mathrm{mM}$ ) and TIOAc (bottom, $\mathrm{c}=$ $0.693 \mathrm{mM}$ ) were added at 3 min intervals.

Figure S15: Calorimetric titration of 1 in $\mathrm{LiOH} / \mathrm{H}_{2} \mathrm{O}(1 \mathrm{M})$ at $298 \mathrm{~K}$ in presence (or not) of $\mathrm{RbCl}$ (top left), $\mathrm{CsOH}$ (top right) or TIOAc (bottom). The host solution (top left, $\mathrm{c}=98.2 \mu \mathrm{M}$; top right, $\mathrm{c}=99.1$ $\mu \mathrm{M}$; bottom, $\mathrm{c}=29.8 \mu \mathrm{M})$ was placed into the calorimeter cell $(1.4 \mathrm{~mL})$ and 28 successive aliquots (10 $\mu \mathrm{L}$ ) of $\mathrm{RbCl}$ (top left $\mathrm{c}=1.029 \mathrm{mM}$ ), $\mathrm{CsOH}$ (top right, $\mathrm{c}=0.986 \mathrm{mM}$ ) and TIOAc (bottom, $\mathrm{c}=0.493$ $\mathrm{mM}$ ) were added at 3 min intervals.

Figure S16: Thermodynamic parameters $\Delta \mathrm{H}^{0}(\mathrm{kcal} / \mathrm{mol}), \Delta S^{0}(\mathrm{cal} / \mathrm{mol} / \mathrm{K})$ and $\Delta \mathrm{G}^{0}(\mathrm{kcal} / \mathrm{mol})$ of the $\mathrm{M}^{+} @ 1$ complexes $\left(\mathrm{M}^{+}=\mathrm{Rb}^{+}, \mathrm{Cs}^{+}, \mathrm{TI}^{+}\right)$in $\mathrm{LiOH} / \mathrm{H}_{2} \mathrm{O}(0.1 \mathrm{M}$ and $1 \mathrm{M}), \mathrm{NaOH} / \mathrm{H}_{2} \mathrm{O}(0.1 \mathrm{M})$ and $\mathrm{KOH} / \mathrm{H}_{2} \mathrm{O}$ $(0.1 \mathrm{M})$ solutions.

Figure S17: ${ }^{133} \mathrm{Cs}$ NMR spectra of the $\mathrm{Cs}^{+} @(r a c)-1$ complex in $\mathrm{NaOD} / \mathrm{D}_{2} \mathrm{O}(0.1 \mathrm{M})$ at different temperatures: $278,288,298,308,318,328,338$ and $348 \mathrm{~K}$.

Figure S18: ECD spectra recorded at $293 \mathrm{~K}$ of $\mathrm{MM}-1$ in $\mathrm{LiOH} / \mathrm{H}_{2} \mathrm{O}(0.1 \mathrm{M})$ solution (saturated $\mathrm{CHCl}_{3}$ solution) in presence of different amount of a) top spectra: cesium hydroxide. b) bottom spectra: 
thallium acetate solutions. [Host] was $1.310^{-5} \mathrm{M}$ for a) [Host] was $1.3510^{-5} \mathrm{M}$ for $\mathrm{b}$ ) . ECD spectra for higher $\left[\mathrm{Cs}^{+}\right]\left(\left[\mathrm{TI}^{+}\right]\right)$are identical to that recorded for 1 eq. of $\mathrm{Cs}^{+}\left(\mathrm{TI}^{+}\right)$.

Figure S19: ECD spectra recorded at $293 \mathrm{~K}$ of $\mathrm{MM}-1$ in $\mathrm{LiOH} / \mathrm{H}_{2} \mathrm{O}(1 \mathrm{M})$ in presence of different amount of a) top spectra: cesium hydroxide. b) bottom spectra: thallium acetate solutions. [Host] was $1.4510^{-5} \mathrm{M}$ for a) [Host] was $1.310^{-5} \mathrm{M}$ for b). ECD spectra for higher $\left[\mathrm{Cs}^{+}\right]\left(\left[\mathrm{TI}^{+}\right]\right)$are identical to that recorded for 1 eq. of $\mathrm{Cs}^{+}\left(\mathrm{TI}^{+}\right)$.

Figure S20: ECD spectra recorded at $293 \mathrm{~K}$ of $\mathrm{MM}-1$ in $\mathrm{KOH} / \mathrm{H}_{2} \mathrm{O}(0.1 \mathrm{M})$ solution in presence of different amount of a) top spectra: cesium hydroxide. b) bottom spectra: thallium acetate solutions. [Host] was $1.310^{-5} \mathrm{M}$ for a) [Host] was $1.310^{-5} \mathrm{M}$ for b). ECD spectra for higher [Cs $\left.{ }^{+}\right]\left(\left[\mathrm{TI}^{+}\right]\right)$are identical to that recorded for 1 eq. of $\mathrm{Cs}^{+}\left(\mathrm{TI}^{+}\right)$.

S25 - S28: DFT calculations (Geometry, Energy decomposition analysis, Non Covalent Interaction, Orbital mixing, Nuclear magnetic shielding). 


\section{Experimental Section}

Separation of the two enantiomers of 6 . The two enantiomers of 6 were separated on a semipreparative Chiralpak-ID $(250 \times 10 \mathrm{~mm})$ chromatographic column. A mixture of Ethanol/ $\mathrm{CH}_{2} \mathrm{Cl}_{2}(20: 80)$ was used as a mobile phase (flow rate: $5 \mathrm{~mL} / \mathrm{min}$ ). UV detection was performed at $254 \mathrm{~nm}$. $550 \mathrm{mg}$ of racemic compound 6 have been dissolved in $15 \mathrm{~mL}$ of dichloromethane and 125 injections $(120 \mu \mathrm{L}$ every 3 minutes) have been necessary to complete the experiment. The first eluted enantiomer has been collected between 3.3 and 4 minutes and the second one between 4.4 and 5.6 minutes. $270 \mathrm{mg}$ of the first eluted enantiomer ((-)-enantiomer) has been isolated with an enantiomeric excess ee > $99 \%$. Then, $270 \mathrm{mg}$, of the second eluted enantiomer ((+)-enantiomer) has been isolated with an enantiomeric excess ee $>99 \%$.

Synthesis of compound PP-7. Freshly prepared lithium diphenylphosphide (1 M; $6.2 \mathrm{~mL})$ was added under argon to a stirred solution of cryptophane MM-6 $(250 \mathrm{mg}, 0.26 \mathrm{mmol})$ in THF $(3 \mathrm{~mL})$. The red mixture was stirred for 48 hours at $60^{\circ} \mathrm{C}$. Then, it was poured in water. The aqueous phase was washed five times with $\mathrm{CH}_{2} \mathrm{Cl}_{2}(50 \mathrm{~mL})$. The aqueous phase was then collected and cooled to $0^{\circ} \mathrm{C}$. Acidification with conc. $\mathrm{HCl}$ solution gives rise to a white precipitate, which was collect on a frit. The white solid was washed several times with water and dried on air. Finally, the solid was washed with diethyl ether to give compound MM-1 as a white powder $(0.21 \mathrm{~g} ; 97 \%)$. This compound contains trace of impurities and an additional purification step is necessary. Thus, compound MM-1 $(0.21 \mathrm{~g}, 0.25$ mmol) was added in a $25 \mathrm{~mL}$ round bottom flask with $7 \mathrm{~mL}$ of dry pyridine. The flask was cooled to $0^{\circ} \mathrm{C}$. Then, anhydride acetic $(1.4 \mathrm{~mL})$ was added under an argon atmosphere. After addition, the flask was allowed to reach room temperature and the mixture was stirred for 5 hours at room temperature. Then, the solution was poured in a mixture of $\mathrm{CH}_{2} \mathrm{Cl}_{2}$ and $\mathrm{H}_{2} \mathrm{O}$. The aqueous phase was extracted three times with $\mathrm{CH}_{2} \mathrm{Cl}_{2}$. The combined organic phase were washed once with water and then dried over $\mathrm{Na}_{2} \mathrm{SO}_{4}$. Evaporation of the solvent under reduced pressure gives rise to a solid residue, which was purified on silica gel $\left(\mathrm{CH}_{2} \mathrm{Cl}_{2} /\right.$ Acetone: 90/10). Different fractions were evaporated to give compound PP-7 as a white glassy solid (0.22 g; $78 \%$ ). ${ }^{1} \mathrm{H}$ NMR $\left(300 \mathrm{MHz}, \mathrm{CD}_{2} \mathrm{Cl}_{2}, 25^{\circ} \mathrm{C}\right) \delta 6.84(\mathrm{~s}, 2$ H), $6.90(\mathrm{~s}, 4 \mathrm{H}), 6.85(\mathrm{~s}, 1 \mathrm{H}), 6.84(\mathrm{~s}, 1 \mathrm{H}), 6.82(\mathrm{~s}, 1 \mathrm{H}), 6.81(\mathrm{~s}, 1 \mathrm{H}), 6.69(\mathrm{~s}, 1 \mathrm{H}), 6.66(\mathrm{~s}, 1 \mathrm{H})$, $5.15(\mathrm{~m}, 1 \mathrm{H}), 4.625(\mathrm{~d}, J=13.8 \mathrm{~Hz}, 4 \mathrm{H}), 4.61(\mathrm{~d}, J=13.8 \mathrm{~Hz}, 2 \mathrm{H}), 4.30-3.85(\mathrm{~m}, 12 \mathrm{H}), 3.51(\mathrm{~d}, J=$ $13.8 \mathrm{~Hz}, 2 \mathrm{H}$ ), 3.495 (d, $J=13.8 \mathrm{~Hz}, 2 \mathrm{H}$ ), 3.49 (d, J=13.8 Hz, $2 \mathrm{H}$ ), 2.34 (s, $\left.9 \mathrm{H} ; \mathrm{OCH}_{3}\right), 2.32(\mathrm{~s}, 3 \mathrm{H}$; $\mathrm{OCH}_{3}$ ), 2.31 (s, $3 \mathrm{H} ; \mathrm{OCH}_{3}$ ), 2.30 (s, $3 \mathrm{H} ; \mathrm{OCH}_{3}$ ), 2.07 ppm (s, $\left.3 \mathrm{H} ; \mathrm{OCH}_{3}\right) ;{ }^{13} \mathrm{C} \mathrm{NMR}(75.4 \mathrm{MHz}$, 
$\left.\mathrm{CH}_{2} \mathrm{Cl}_{2}, 25^{\circ} \mathrm{C}\right) \delta 171.4(2 \mathrm{C}), 170.1(4 \mathrm{C}), 169.9(2 \mathrm{C}), 150.4(2 \mathrm{C}), 150.3,150.2,149.9,149.6,141.9$ (2C), 141.8, 141.7, 140.6, 140.3, 139.7, 139.4, 139.3, 139.2, 138.7, 138.4, 135.0, 134.9 (2C), 134.6, 133.5, 133.2, 126.2, 126.1, 125.7, 125.6, 125.2, 124.6, 122.0, 121.6, 121.4, 121.3, 115.9, 115.3, 71.9, $70.8(3 \mathrm{C}), 70.4,66.2,65.7,37.8,37.7,37.4(4 \mathrm{C}), 22.2(6 \mathrm{C}), 22.0 \mathrm{ppm}$. The ${ }^{1} \mathrm{H}$ and ${ }^{13} \mathrm{C}$ NMR spectra of compound MM-7 are identical to that of PP-7.

Synthesis of $M M-1$. A solution of $\mathrm{KOH} / \mathrm{H}_{2} \mathrm{O}(0.5 \mathrm{M} ; 7 \mathrm{~mL})$ was added in one portion to compound $P P$ $7(0.22 \mathrm{~g}, 0.19 \mathrm{mmol})$ in THF $(7 \mathrm{~mL})$. The mixture was overnight stirred at $50^{\circ} \mathrm{C}$ under an argon atmosphere. Then, THF was removed under reduced pressure. $7 \mathrm{~mL}$ of water were added and the flask was cooled to $0^{\circ} \mathrm{C}$. Acidification with few drops of conc. $\mathrm{HCl}$ gives rise to a white solid, which was collected on a frit and washed several times with water. The solid was then dried on the frit and washed with diethyl ether to give compound $M M-1$ as a beige solid $(0.16 \mathrm{~g} ; 98 \%) .{ }^{1} \mathrm{H}$ NMR $(300 \mathrm{MHz}$, DMSO- $\left.d_{6}, 25^{\circ} \mathrm{C}\right) \delta 8.57(\mathrm{~s}, 1 \mathrm{H}), 8.48(\mathrm{~s}, 1 \mathrm{H}), 8.43(\mathrm{~s}, 1 \mathrm{H}), 8.31(\mathrm{~s}, 1 \mathrm{H}), 8.14(\mathrm{~s}, 1 \mathrm{H}), 7.91(\mathrm{~s}, 1 \mathrm{H})$, $6.77(\mathrm{~s}, 1 \mathrm{H}), 6.74(\mathrm{~s}, 1 \mathrm{H}), 6.69-6.62(\mathrm{~m}, 8 \mathrm{H}), 6.55(\mathrm{~s}, 1 \mathrm{H}), 6.54(\mathrm{~s}, 1 \mathrm{H}), 5.31(\mathrm{~s}, 1 \mathrm{H}), 4.50-3.70$ $(\mathrm{m}, 18 \mathrm{H}), 3.22(\mathrm{~m}, 6 \mathrm{H}) .{ }^{13} \mathrm{C}$ NMR $\left(75.4 \mathrm{MHz}\right.$, DMSO- $\left.d_{6}, 25^{\circ} \mathrm{C}\right) \delta 146.4,146.35,145.7,145.6,145.5$, 145.4, 145.3, 145.1, 144.5, 144.3 (2 C), 144.1, 133.9, 133.8, 133.6, 133.5, 133.3 (2 C), 131.1 (2 C), 130.5 (2 C), 129.5, 128.9, 120.2, 119.8, 119.0, 118.1 (2 C), 118.0, 117.6, 117.5, 117.4, 117.0, 116.9, 116.5. $71.5,70.5,69.2,68.5$ (3C), 68.2, 68.1, 35.1, 34.9, 34.8 HRMS m/z $[\mathrm{M}+\mathrm{H}]^{+}$calcd. for $\mathrm{C}_{49} \mathrm{H}_{45} \mathrm{O}_{13}$ 841.2892 found. 841.2855 .

Using the same synthetic approach derivative PP-6 $(0.24 \mathrm{~g}, 0.25 \mathrm{mmol})$ gives rise to $M M-7(0.2 \mathrm{~g}$; $71 \%, 2$ steps). In turn, hydrolysis of compound $M M-7$ under basic solution gives compound $P P-1$ $(0.13 \mathrm{~g} ; 88 \%)$ as a beige solid. Spectroscopic data are identical to those reported for the $M M-1$ enantiomer.

ECD measurements. ECD spectra were recorded at $293 \mathrm{~K}$ using $0.2 \mathrm{~cm}$ path length quartz cells. The concentration of the MM-1 derivative was in the range $\left(5.010^{-5}-10^{-5} \mathrm{M}\right)$ in basic $\mathrm{LiOH} / \mathrm{H}_{2} \mathrm{O}$ or $\mathrm{KOH} / \mathrm{H}_{2} \mathrm{O}$ solutions. Additional ECD spectra were recorded at higher $\mathrm{LiOH} / \mathrm{H}_{2} \mathrm{O}$ concentration $(1 \mathrm{M})$ or in the presence of a competitor (saturated $\mathrm{LiOH} / \mathrm{H}_{2} \mathrm{O}$ solution with $\mathrm{CHCl}_{3}$ ). Spectra were recorded in the $220-400 \mathrm{~nm}$ spectral range with a $0.5 \mathrm{~nm}$ increment and a $1 \mathrm{~s}$ integration time. Spectra were processed with standard spectrometer software and baseline corrected without smoothing. Spectral units are expressed in difference in molar extinction coefficients. 
VCD measurements. The IR and VCD spectra were recorded on a FTIR spectrometer equipped with a VCD optical bench. ${ }^{[1]}$ following the experimental procedure previously published. ${ }^{[2]}$ Samples were held in a $\mathrm{CaF}_{2}$ cell with a fixed path length of $45 \mu \mathrm{m}$. IR and VCD spectra of the two enantiomers of 1 were measured in basic $\mathrm{NaOD} / \mathrm{D}_{2} \mathrm{O}(0.214 \mathrm{M})$ solution at a concentration of $0.030 \mathrm{M}$. Additional spectra were recorded in the presence of a very small amount of $\mathrm{CDCl}_{3}$ and $\mathrm{CsOH}$.

ITC experiments. Isothermal Titration Calorimetry (ITC) experiments were performed at $298 \mathrm{~K}$. In a typical experiment, the host solution $(\sim 0.1 \mathrm{mM})$ in $\mathrm{LiOH} / \mathrm{H}_{2} \mathrm{O}(0.1 \mathrm{M})$ or $\mathrm{KOH} / \mathrm{H}_{2} \mathrm{O}(0.1 \mathrm{M})$ was placed in the calorimeter cell $(1.4 \mathrm{~mL})$ and 28 successive aliquots $(10 \mu \mathrm{L})$ of guest solution (10 times more concentrated) were added via a computer-automated injector at $3 \mathrm{~min}$ intervals. Heat changes were recorded after each addition. Heats of dilution were measured by a blank experiment (in the absence of host) under the same conditions, and they were subtracted from the titration data prior to curve fitting. The first injection was discarded from each data set to remove the effect of guest diffusion across the syringe tip during the equilibration process. Titration curves were fitted with the one binding set model. In the case of very high binding for the $\mathrm{Cs}^{+} @(r a c)-1$ and $\mathrm{TI}^{+} @(r a c)-1$ complexes, competition experiments were necessary. In our case, $\mathrm{RbCl}$ was a good competitor since it shows lower affinity with host 1 . Thus, prior to measure enthalpogram for the $\mathrm{Cs}^{+} @ 1$ and the $\mathrm{TI}^{+} @ 1$ complexes, the association constant $\mathrm{K}$ and the enthalpy of complexation $\Delta \mathrm{H}^{0}$ of the $\mathrm{Rb}^{+} @ 1$ complex were measured. Additional ITC experiments were performed at higher $\mathrm{LiOH} / \mathrm{H}_{2} \mathrm{O}(1 \mathrm{M})$ concentration under the same conditions. In this case, competition experiments were not necessary.

NMR experiments. ${ }^{133} \mathrm{Cs}$ NMR spectra were recorded on an $11.7 \mathrm{~T}$ Bruker Avance spectrometer using a $5 \mathrm{~mm}$ broadband probehead. A solution of cesium nitrate was used as a chemical shift reference $(0 \mathrm{ppm})$. A delay time of $1 \mathrm{~s}$ was applied between each pulse. At $298 \mathrm{~K}$ the delay time was 5 s. ${ }^{133} \mathrm{Cs}$ NMR spectra were also recorded at different temperature $(278-348 \mathrm{~K})$. The ${ }^{205} \mathrm{TI}$ NMR experiments were performed on a Bruker DMX300 spectrometer (7 Tesla) equipped with a $5 \mathrm{~mm} \mathrm{BB}$ Nalorac probehead recovered from a 11.7 Tesla spectrometer. First, a solution of thallium nitrate was used as a chemical shift reference $(0 \mathrm{ppm})$. Then, the other spectra were recorded by part. The interscan delay was $0.9 \mathrm{~s}$. For all the displayed ${ }^{205} \mathrm{TI}$ NMR spectra the FIDs were processed by an exponential window of $200 \mathrm{~Hz}$ before Fourier transformation.

DFT Calculations. DFT calculations were performed using the ORCA and ADF program packages. ${ }^{[3],[4]}$ To calculate NMR parameters, the two-component method of relativistic quantum chemistry was 
used in the framework of the zeroth-order regular approximation (ZORA) and all-electron basis sets. ${ }^{[5]}$ The non-covalent interactions were analyzed and visualized with MULTIWFN and VMD programs. ${ }^{[6],[7]}$ A comprehensive description of the used methods is provided in Supporting Information. 
Analytical chiral HPLC separation for compound 6

\begin{tabular}{cccccccc} 
Column & Mobile Phase & $\mathrm{t}_{1}$ & $\mathrm{k}_{1}$ & $\mathrm{t}_{2}$ & $\mathrm{k}_{2}$ & $\alpha$ & $\mathrm{Rs}$ \\
Chiralpak ID & $\mathrm{EtOH} / \mathrm{CH}_{2} \mathrm{Cl}_{2} 20 / 80$ & $3.84(-)$ & 0.28 & $5.33(+)$ & 0.78 & 2.79 & 5.04 \\
\hline
\end{tabular}
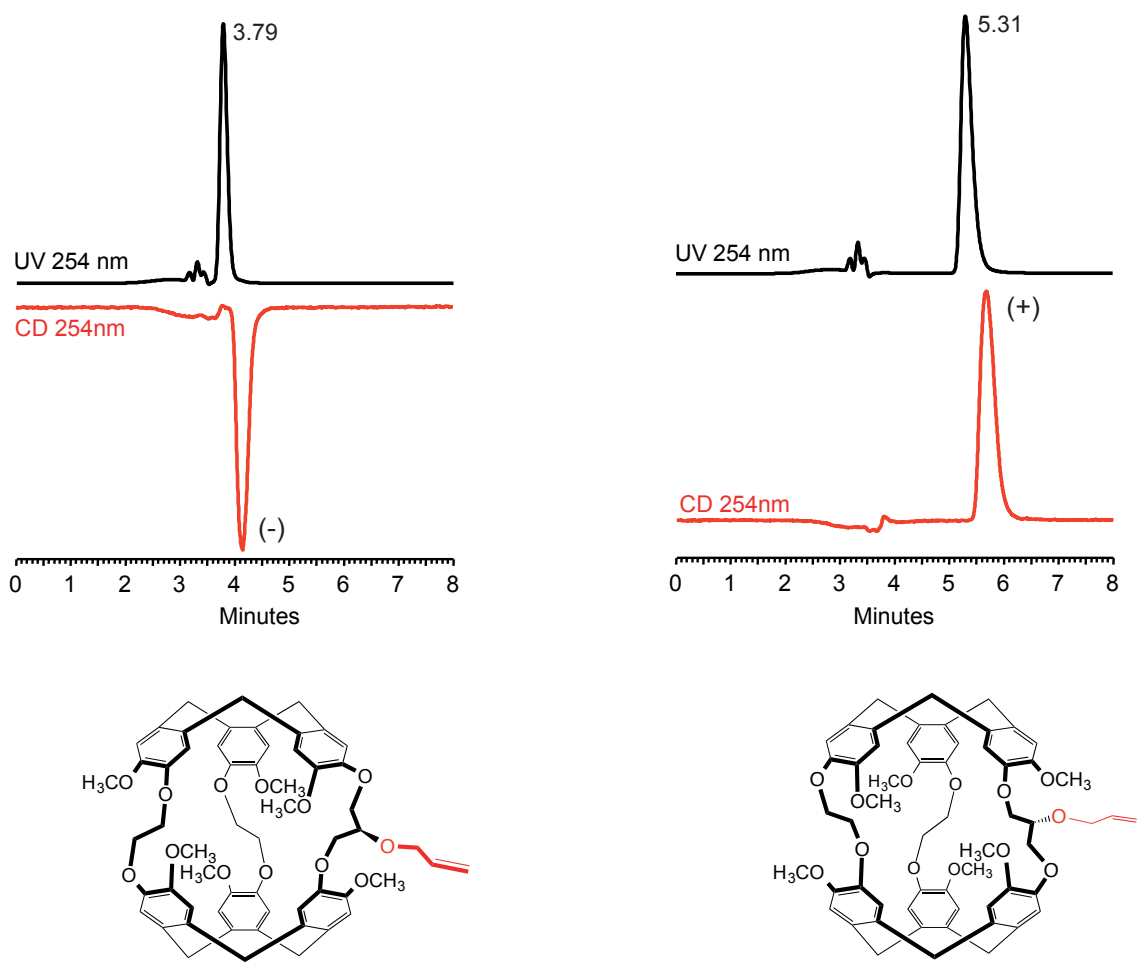

$M M-(-)$

$P P-(+)$

Figure S1: Chromatograms (Chiralpak ID, $250 \times 4.6 \mathrm{~mm}, \mathrm{EtOH} / \mathrm{CH}_{2} \mathrm{Cl}_{2}: 20 / 80,1 \mathrm{~mL} / \mathrm{min}$ ) of the collected anti-6 enantiomers after preparative separation on Chiralpak ID $\left(250 \times 10 \mathrm{~mm}, \mathrm{EtOH} / \mathrm{CH}_{2} \mathrm{Cl}_{2}\right.$ : $20 / 80,5 \mathrm{~mL} / \mathrm{min}$ ) by 120 injections of $4.4 \mathrm{mg}$ of racemate. Detection by UV-vis spectroscopy at 254 $\mathrm{nm}$ (black chromatograms) and CD spectroscopy at $254 \mathrm{~nm}$ (red chromatograms). 

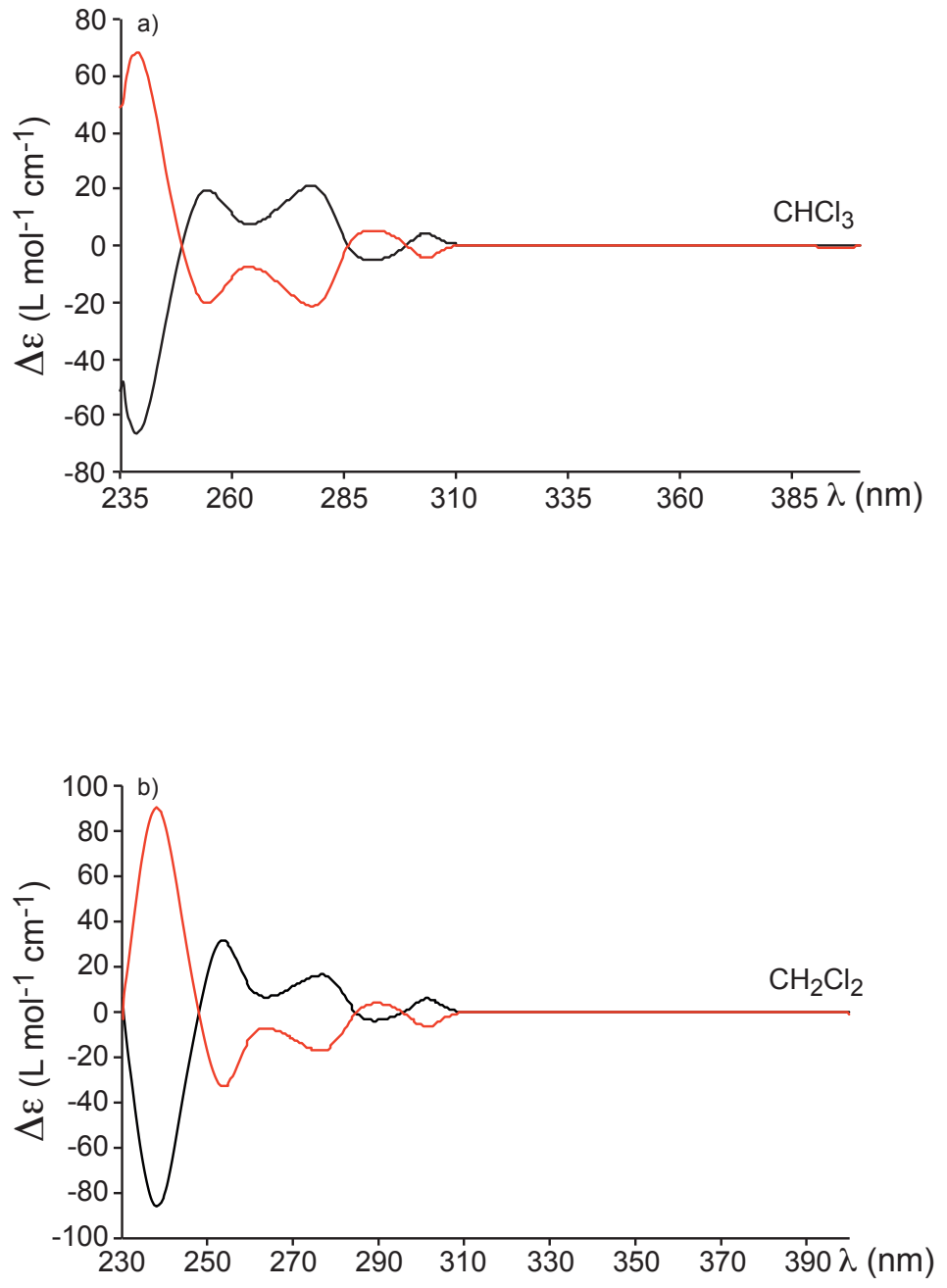

\begin{tabular}{ccrrrrr}
\hline & Conc. $^{\text {[a] }}$ & {$[\alpha]_{589}^{25}$} & {$[\alpha]_{577}^{25}$} & {$[\alpha]_{546}^{25}$} & {$[\alpha]_{436}^{25}$} & {$[\alpha]_{365}^{25}$} \\
\hline MM-6 & 0.24 & -204.9 & -216.2 & -249.5 & -454.7 & -835.0 \\
PP-6 & 0.22 & +200.2 & +210.0 & +239.5 & +443.0 & +820.0 \\
${ }^{[a]} \mathrm{g} / 100 \mathrm{~mL}$. & & & & & &
\end{tabular}

Figure S2: $E C D$ spectra of compound $M M-6$ and $P P-6$ recorded in $\mathrm{CHCl}_{3}$ (a: top spectrum; $\mathrm{c}=1.12$ $10^{-4} \mathrm{M}-9.0410^{-5} \mathrm{M}$ ) and in $\mathrm{CH}_{2} \mathrm{Cl}_{2}$ (b: bottom spectrum; $\mathrm{c}=9.4110^{-5} \mathrm{M}-8.8810^{-5} \mathrm{M}$ ). Polarimetric measurements of compounds $M M-6$ and $P P-6$ recorded at $25^{\circ} \mathrm{C}$ in $\mathrm{CHCl}_{3}$. 


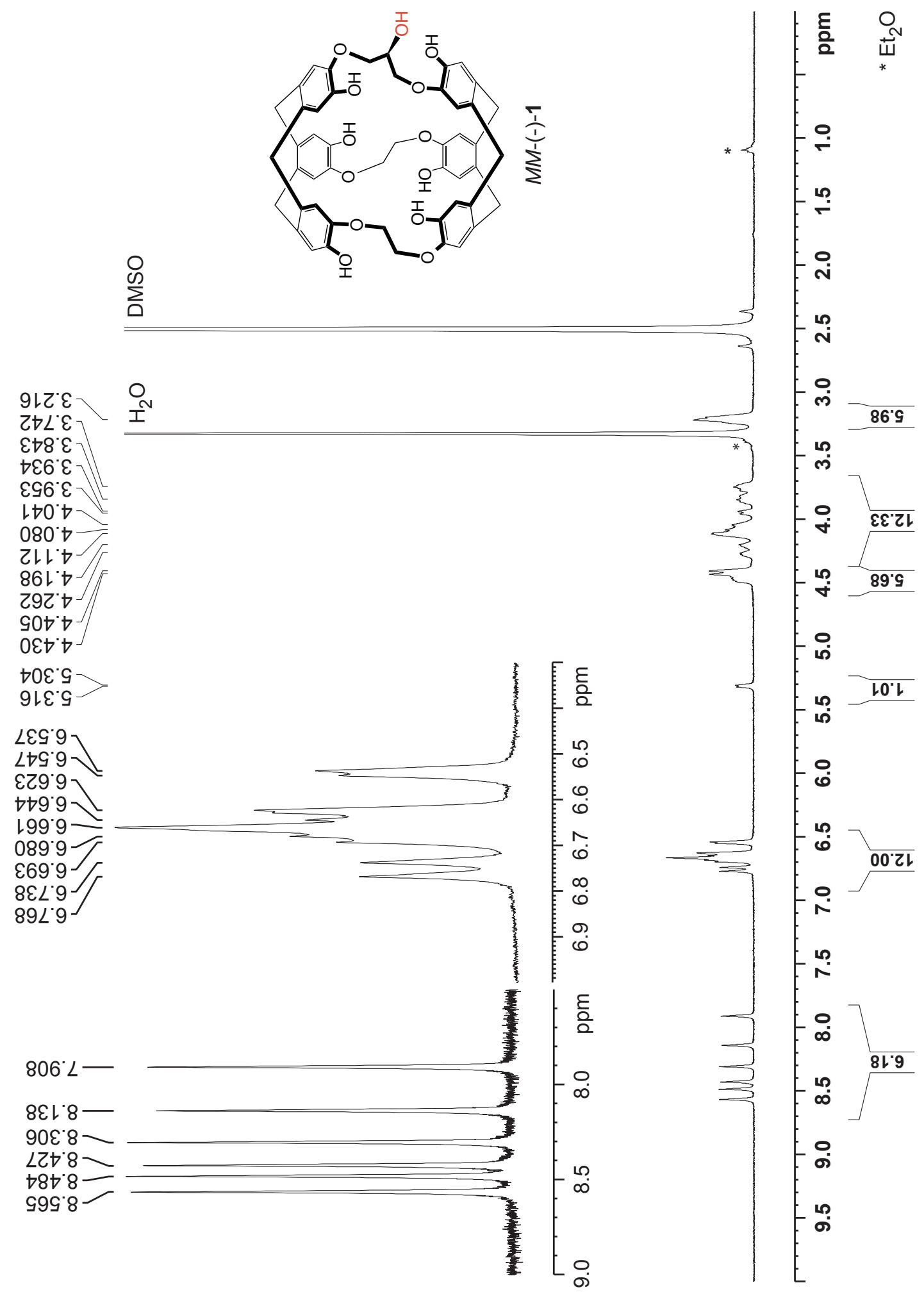

Figure S3: ${ }^{1} \mathrm{H}$ NMR spectrum $(300 \mathrm{MHz})$ of the enantiomer MM-1 recorded in DMSO- $d_{6}$ at $298 \mathrm{~K}$. 


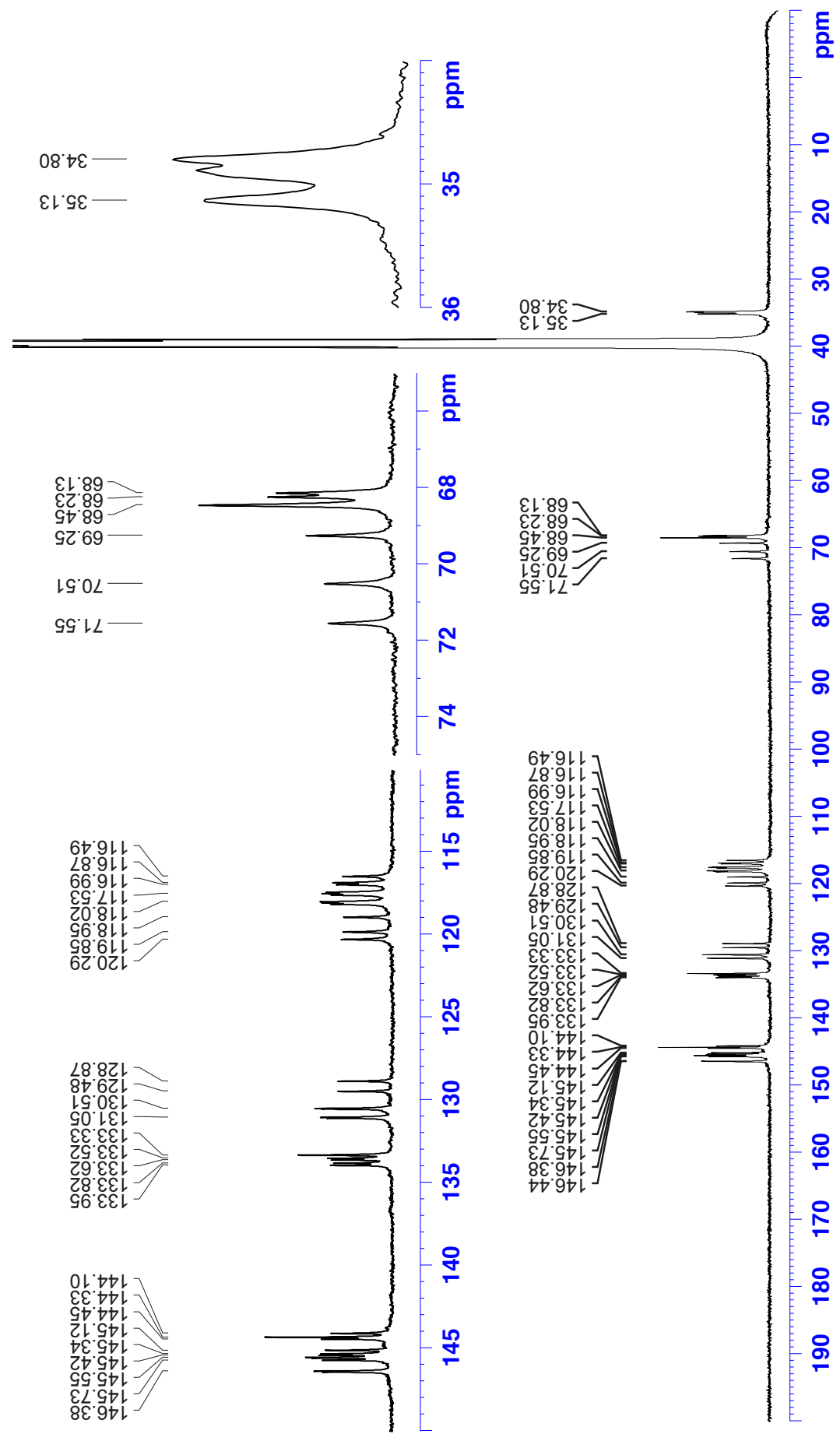

Figure S4: ${ }^{13} \mathrm{C}$ NMR spectrum $(75.47 \mathrm{MHz})$ of the enantiomer $M M-1$ recorded in DMSO- $d_{6}$ at $298 \mathrm{~K}$. 


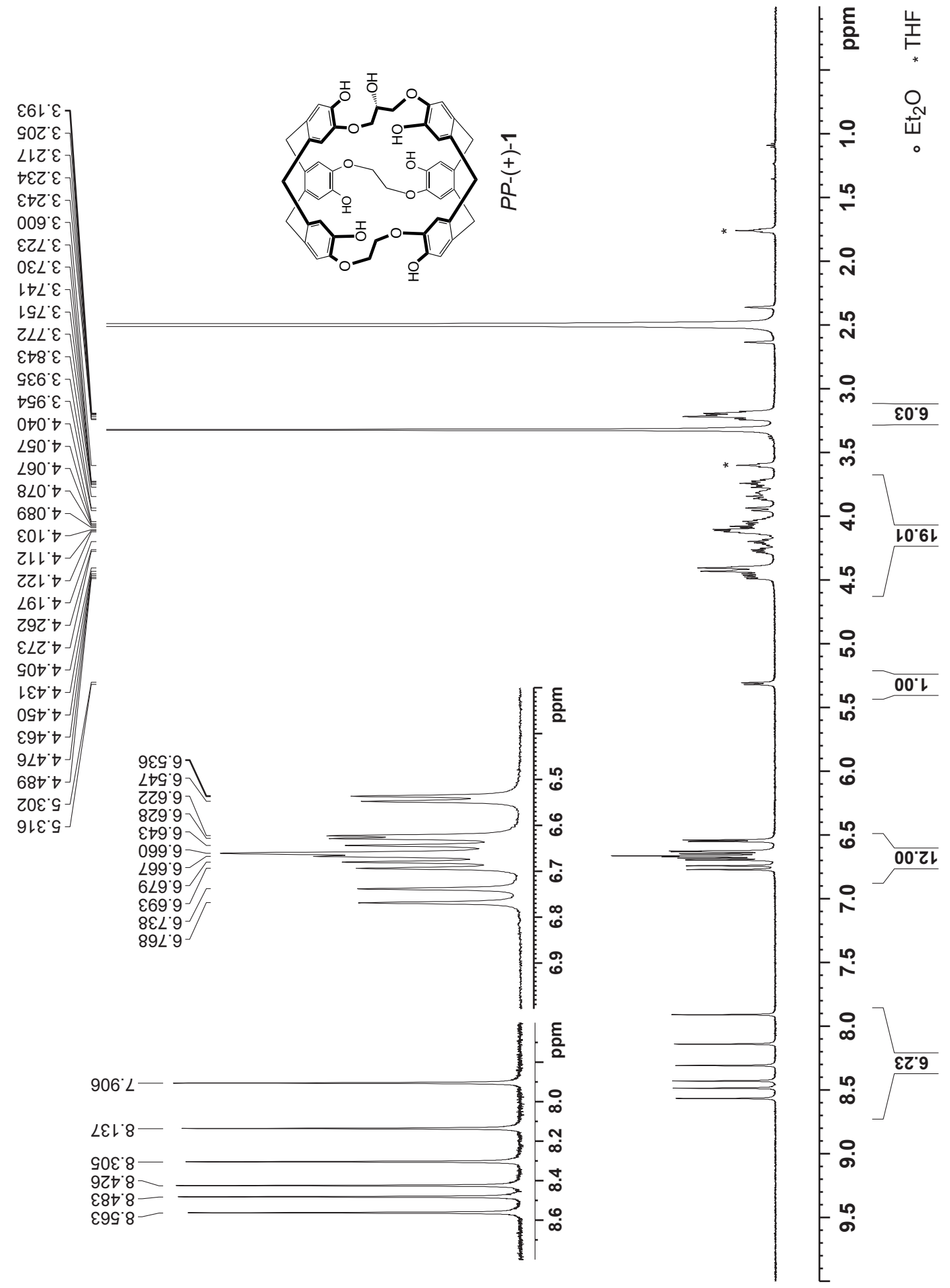

Figure S5: ${ }^{1} \mathrm{H}$ NMR spectrum $(300 \mathrm{MHz})$ of the enantiomer $P P-1$ recorded in DMSO- $d_{6}$ at $298 \mathrm{~K}$. 


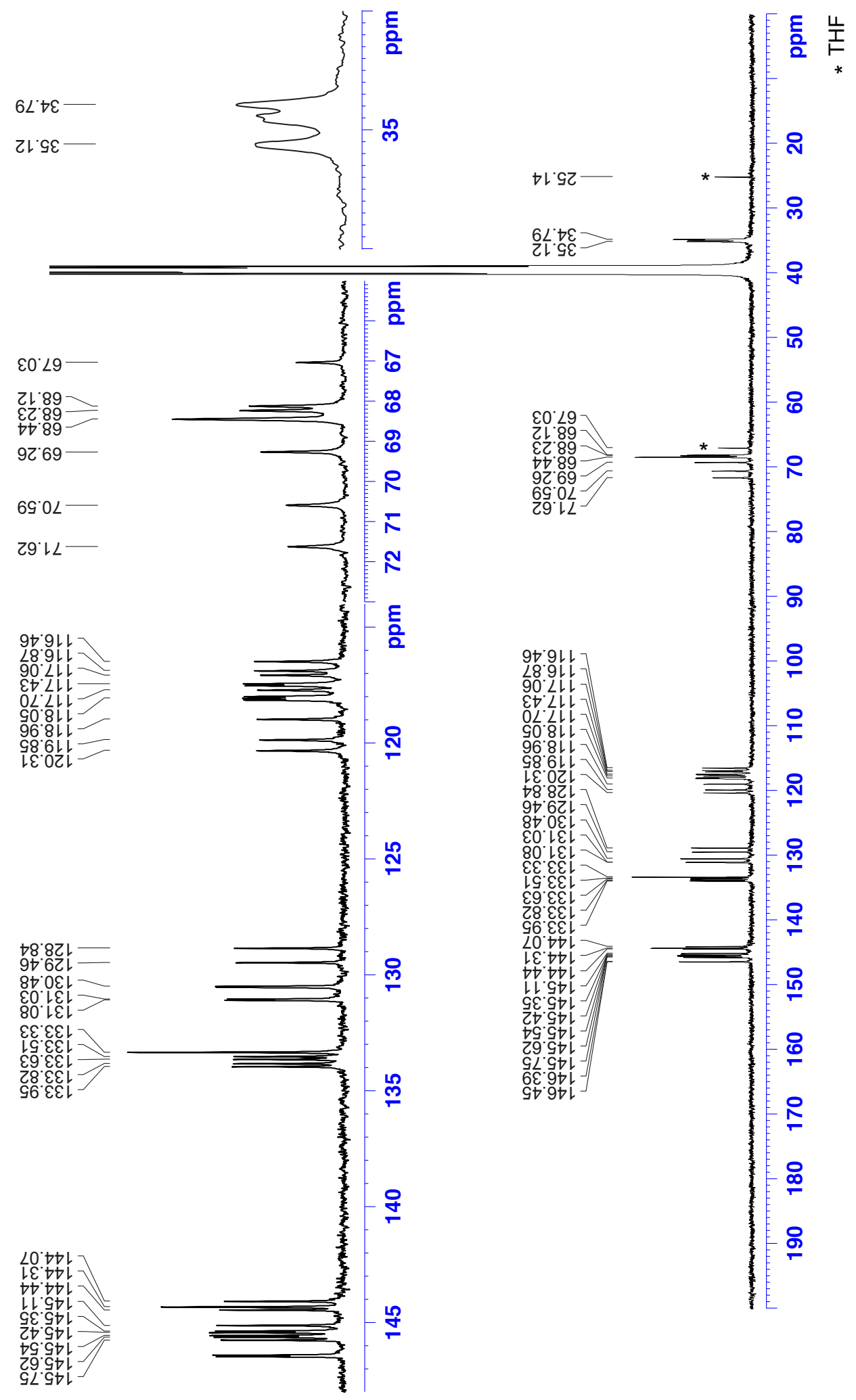

Figure S6: ${ }^{13} \mathrm{C}$ NMR spectrum $(75.47 \mathrm{MHz})$ of the enantiomer $P P-1$ recorded in DMSO- $d_{6}$ at $298 \mathrm{~K}$. 


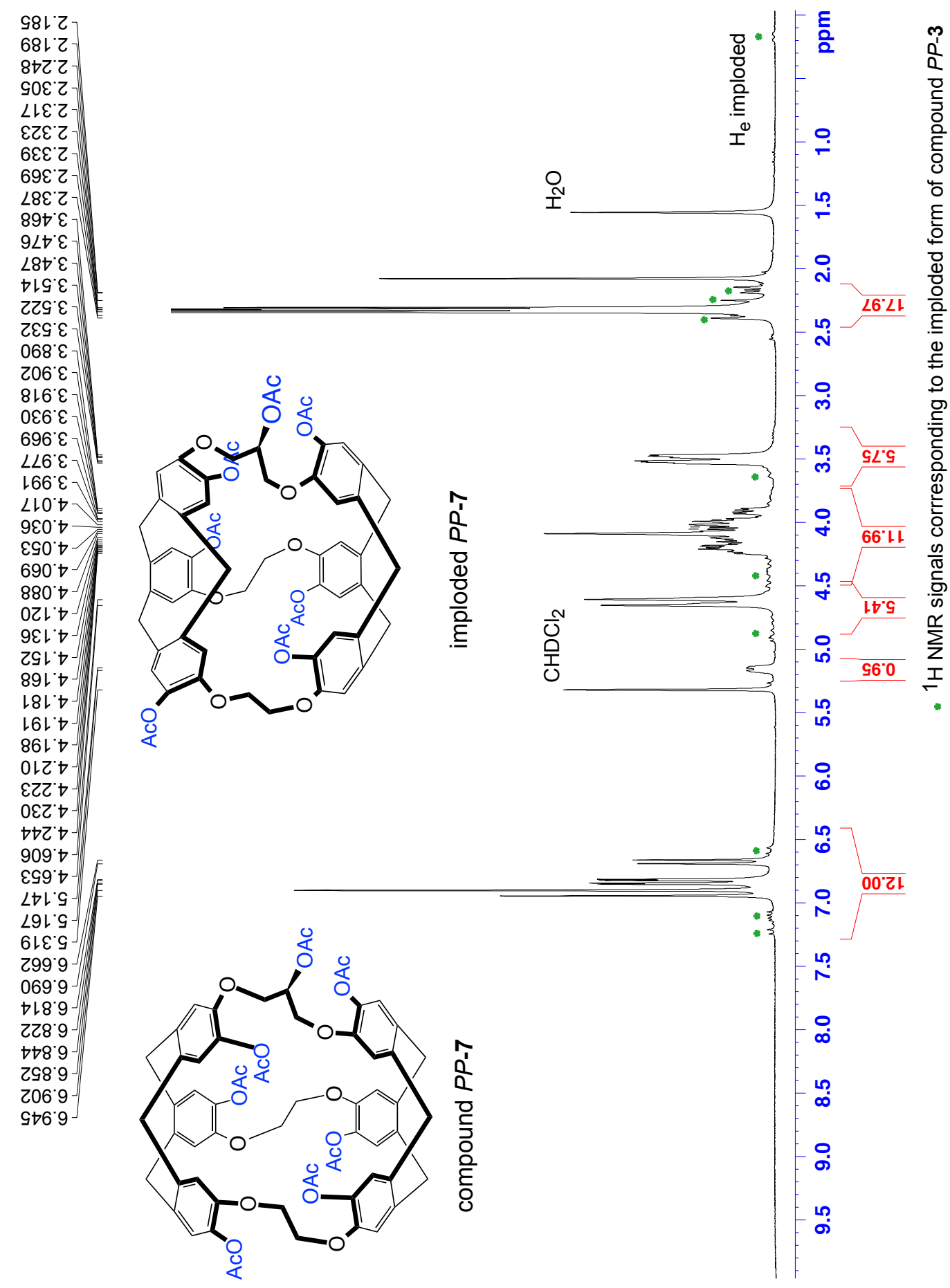

Figure S7: ${ }^{1} \mathrm{H}$ NMR spectrum $(300 \mathrm{MHz}$ ) of the enantiomer PP-7 (non-imploded form) recorded in $\mathrm{CD}_{2} \mathrm{Cl}_{2}$ at $298 \mathrm{~K}$. 

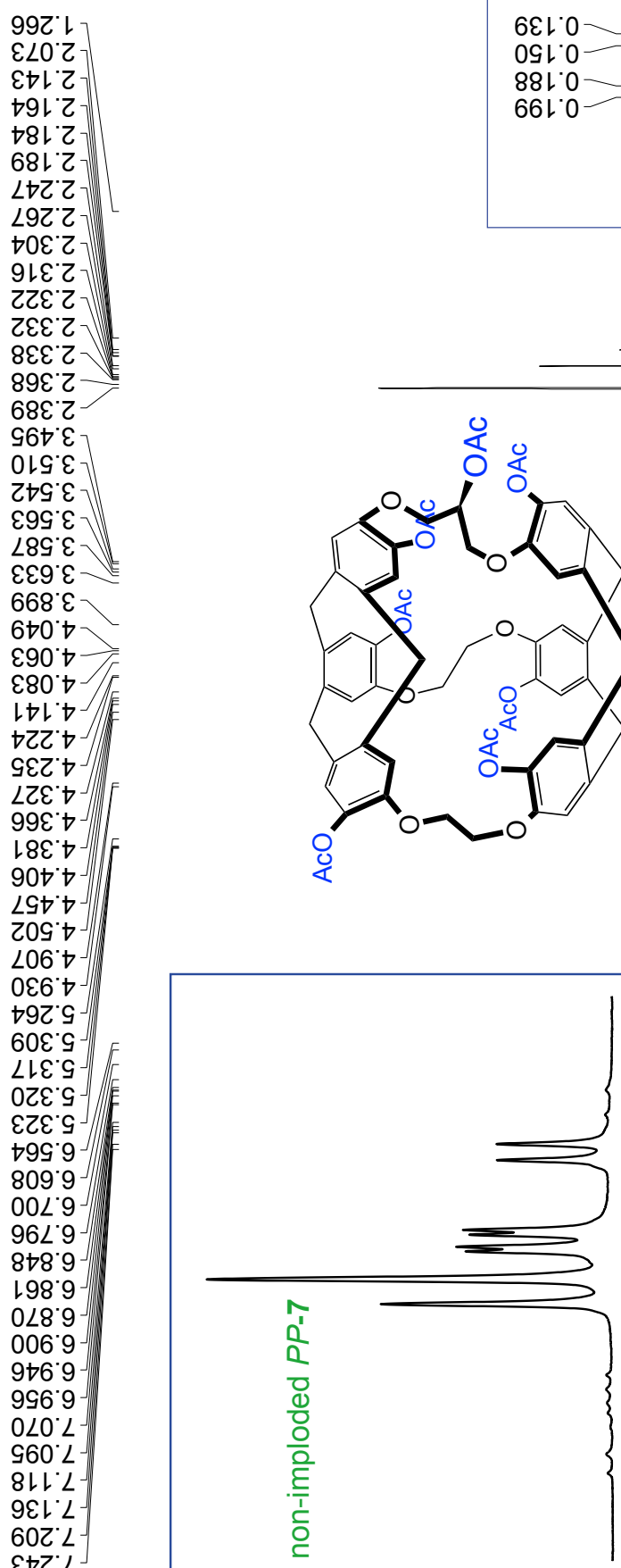

OSLO

$88 \mathrm{~L}^{\circ} \mathrm{O}$

$66 l^{\circ} 0$
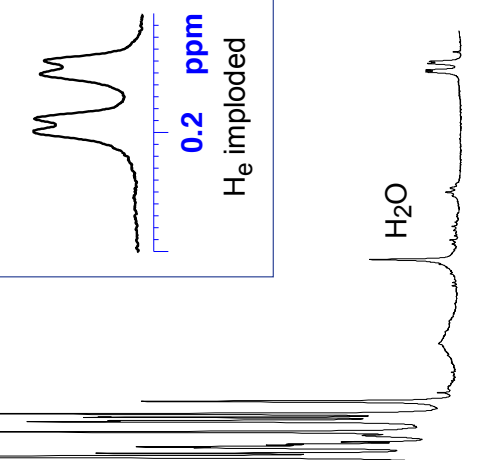

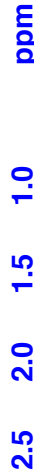

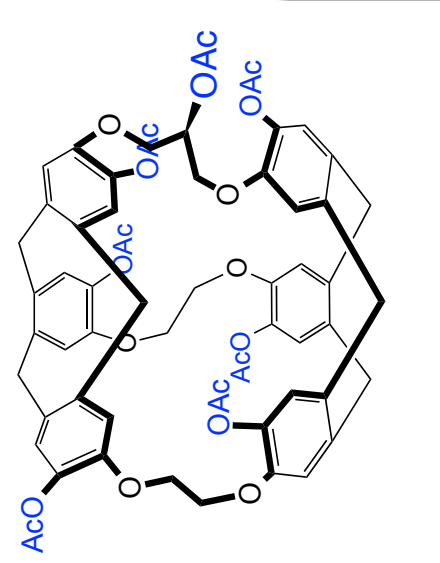

ले

๓)

$\stackrel{0}{+}$

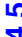

웅

is

นึำ

웅

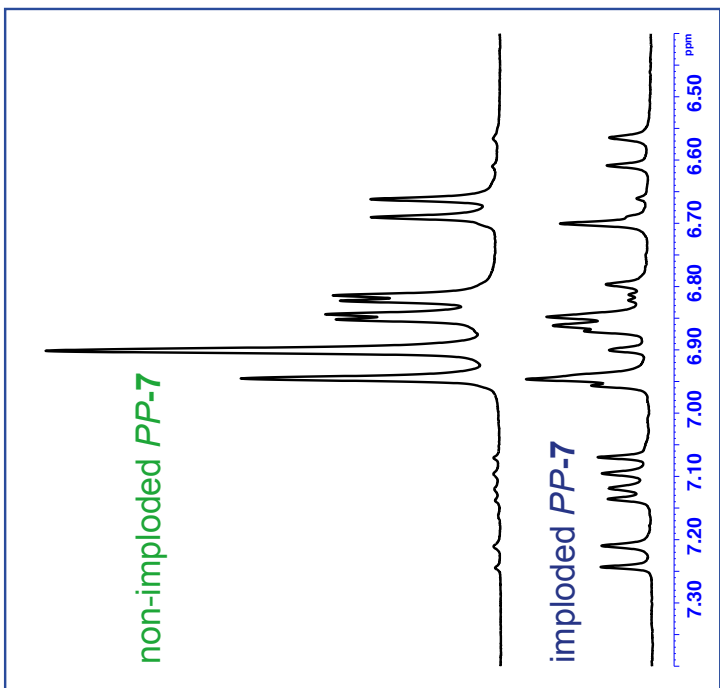

น

$\stackrel{ }{1}$

$\stackrel{\text { ก }}{N}$

$\infty$

ᄂ

우

ต

Figure S8: ${ }^{1} \mathrm{H}$ NMR spectrum $(300 \mathrm{MHz}$ ) of the enantiomer PP-7 (mainly imploded form) recorded in $\mathrm{CD}_{2} \mathrm{Cl}_{2}$ at $298 \mathrm{~K}$. in insert: comparison of the ${ }^{1} \mathrm{H}$ NMR spectra of the imploded and non-imploded form (aromatic region only). 


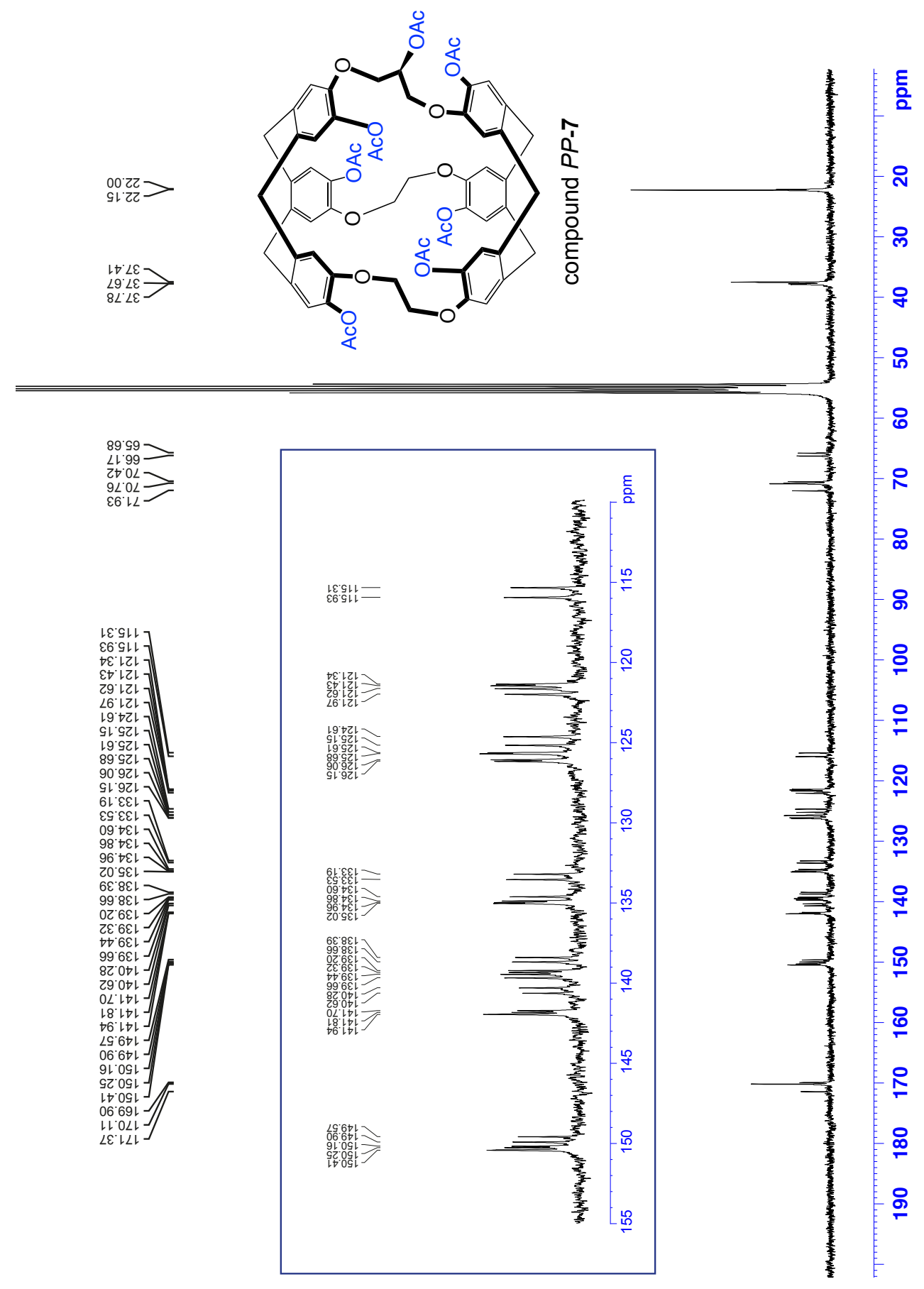

Figure S9: ${ }^{13} \mathrm{C}$ NMR spectrum $(75.47 \mathrm{MHz})$ of the enantiomer PP-7 (non-imploded form) recorded in $\mathrm{CD}_{2} \mathrm{Cl}_{2}$ at $298 \mathrm{~K}$. 


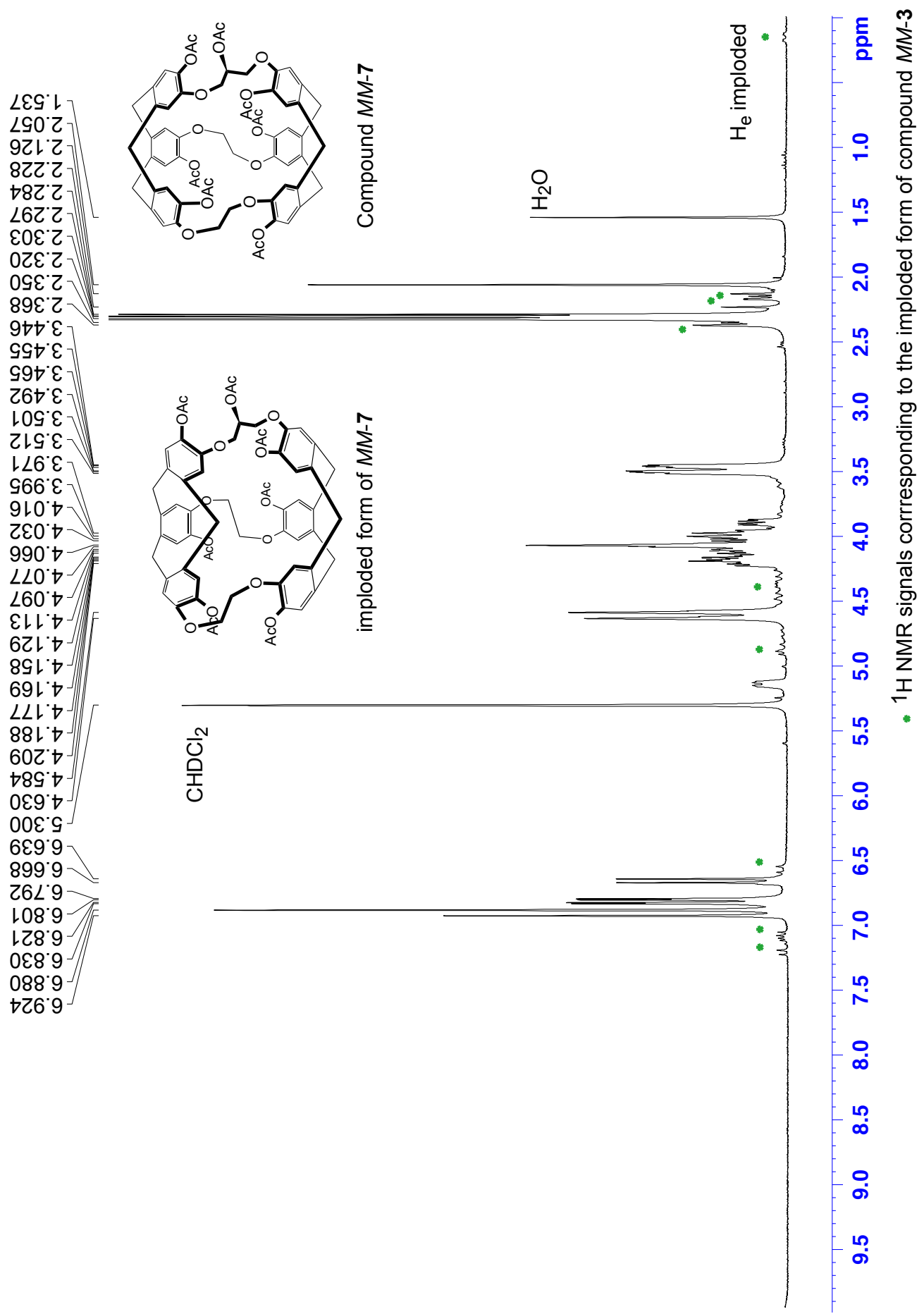

Figure S10: ${ }^{1} \mathrm{H}$ NMR spectrum $(300 \mathrm{MHz})$ of the enantiomer $\mathrm{MM}-7$ recorded in $\mathrm{CD}_{2} \mathrm{Cl}_{2}$ at $298 \mathrm{~K}$. 


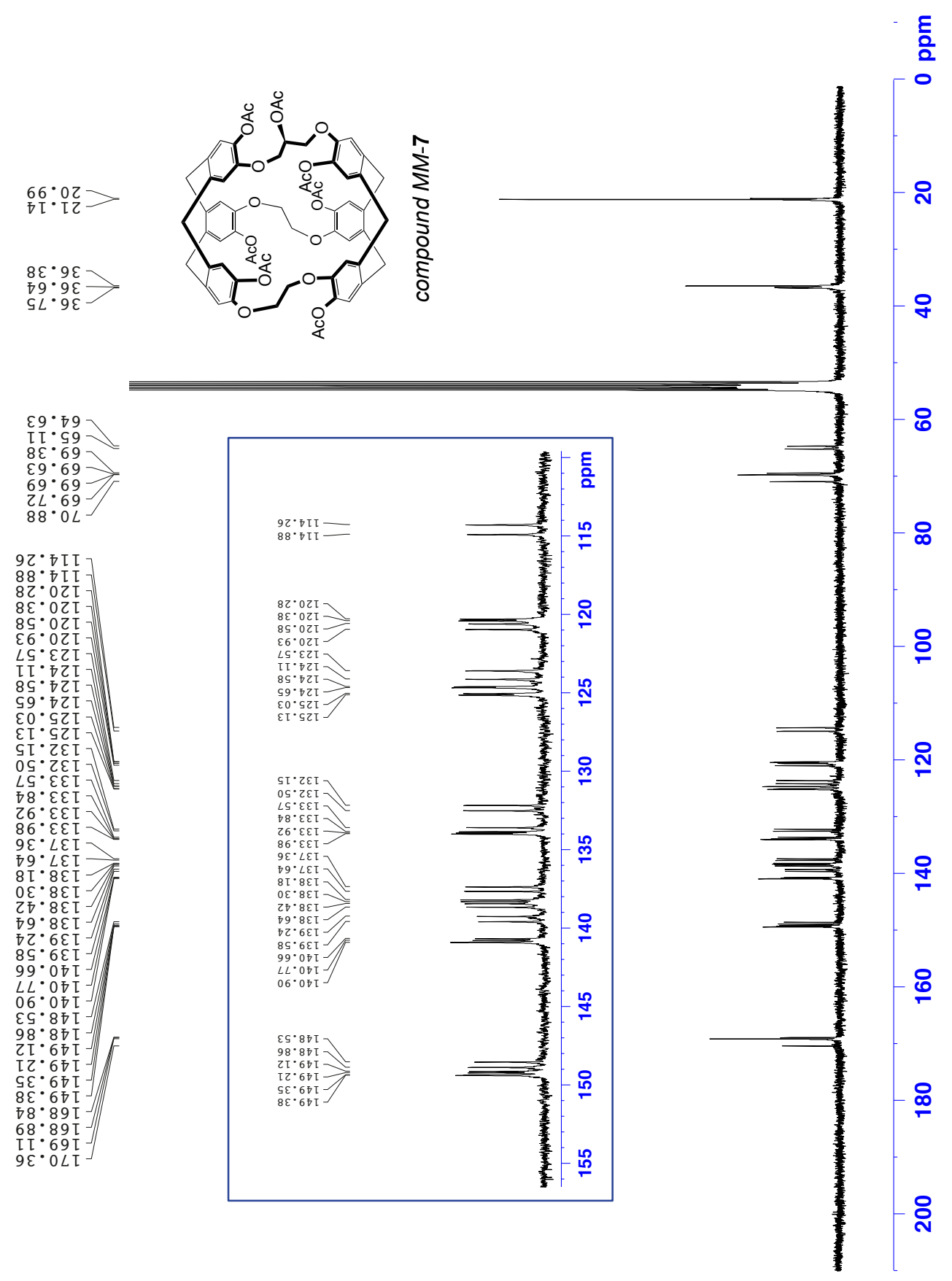

Figure S11: ${ }^{13} \mathrm{C}$ NMR spectrum $(75.47 \mathrm{MHz}$ ) of the enantiomer MM-7 (non-imploded form) recorded in $\mathrm{CD}_{2} \mathrm{Cl}_{2}$ at $298 \mathrm{~K}$. 

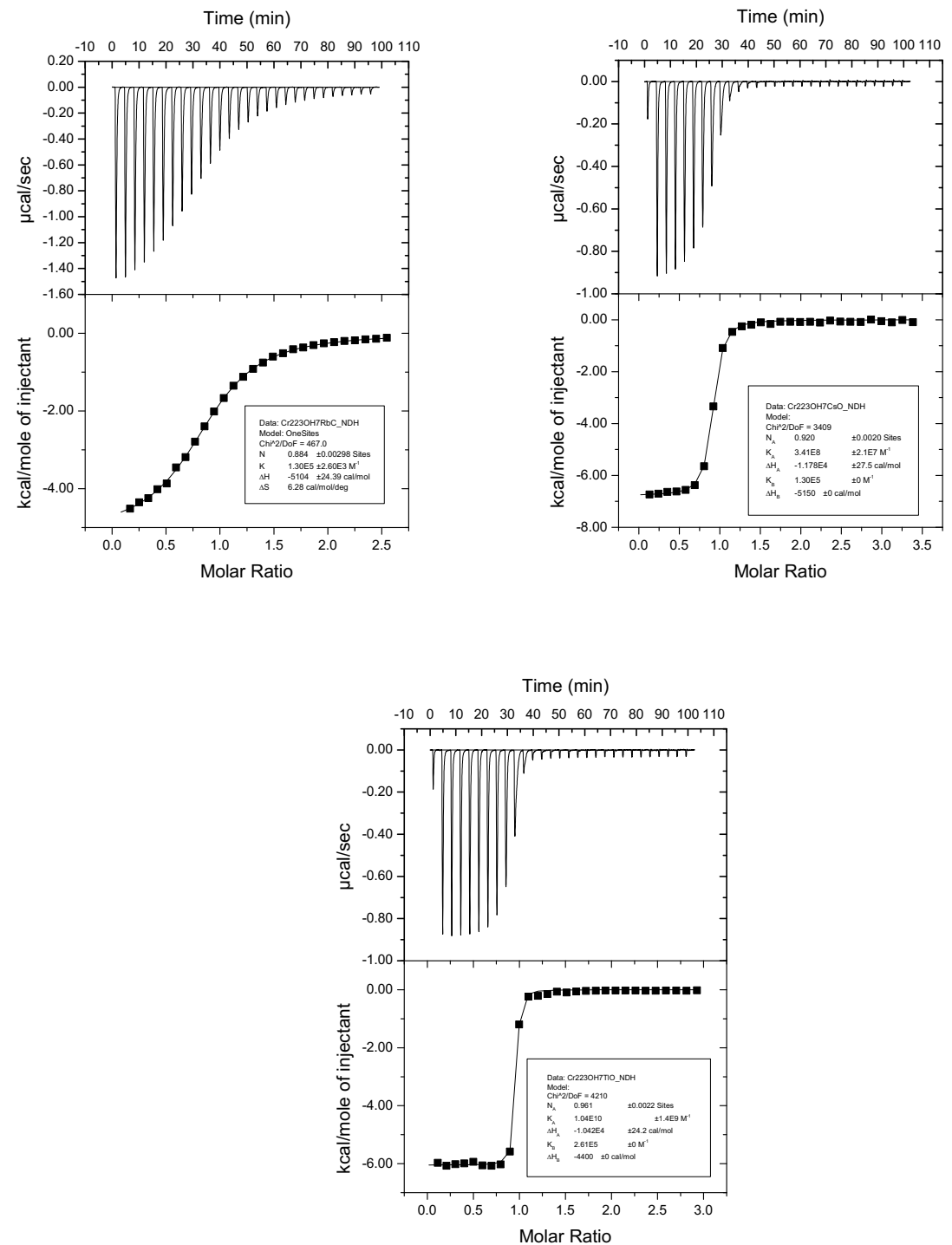

Figure S12: Calorimetric titration of $1 \mathrm{in} \mathrm{LiOH} / \mathrm{H}_{2} \mathrm{O}(0.1 \mathrm{M})$ at $298 \mathrm{~K}$ in presence (or not) of $\mathrm{RbCl}$ (top left), $\mathrm{CsOH}$ (top right) or TIOAc (bottom). The host solution (top left, $\mathrm{c}=99.3 \mu \mathrm{M}$; top right, $\mathrm{c}=26.0$ $\mu \mathrm{M}$; bottom, $\mathrm{c}=30.2 \mu \mathrm{M})$ was placed into the calorimeter cell $(1.4 \mathrm{~mL})$ and 28 successive aliquots (10 $\mu \mathrm{L}$ ) of $\mathrm{RbCl}$ (top left $\mathrm{c}=1.029 \mathrm{mM}$ ), $\mathrm{CsOH}$ (top right, $\mathrm{c}=0.404 \mathrm{mM}$ ) and TIOAc (bottom, $\mathrm{c}=0.406$ $\mathrm{mM}$ ) were added at $3 \mathrm{~min}$ intervals. The concentration of $\mathrm{RbCl}$ was: top right, $\mathrm{c}=0.302 \mathrm{mM}$; bottom, $\mathrm{c}$ $=0.598 \mathrm{mM}$ (competition experiments). 

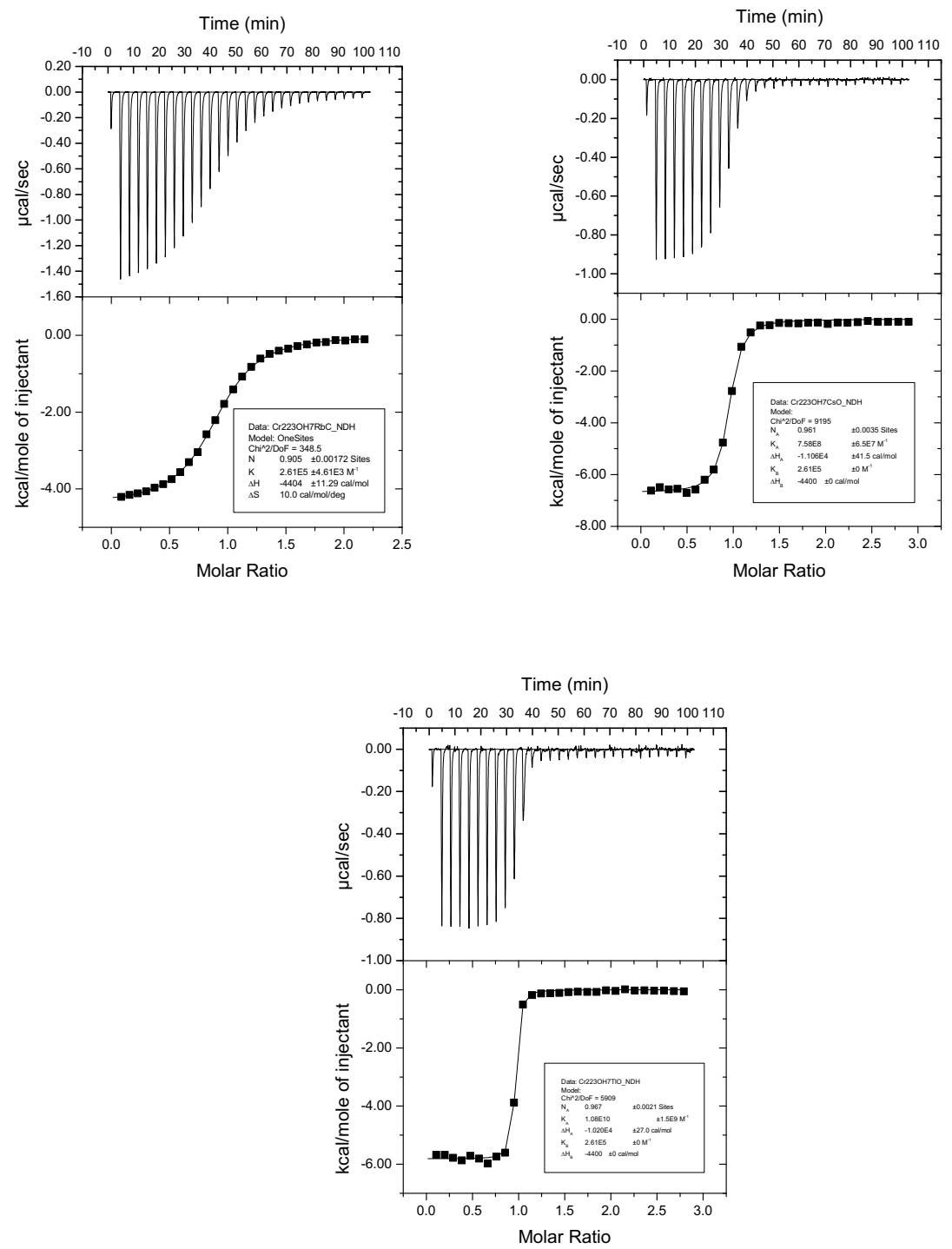

Figure S13: Calorimetric titration of 1 in $\mathrm{NaOH} / \mathrm{H}_{2} \mathrm{O}(0.1 \mathrm{M})$ at $298 \mathrm{~K}$ in presence (or not) of $\mathrm{RbCl}$ (top left), $\mathrm{CsOH}$ (top right) or TIOAc (bottom). The host solution (top left, $\mathrm{c}=100 \mu \mathrm{M}$; top right, $\mathrm{c}=29.9 \mu \mathrm{M}$; bottom, $c=30.2 \mu \mathrm{M})$ was placed into the calorimeter cell $(1.4 \mathrm{~mL})$ and 28 successive aliquots $(10 \mu \mathrm{L})$ of $\mathrm{RbCl}$ (top left $\mathrm{c}=1.0 \mathrm{mM}$ ), $\mathrm{CsOH}$ (top right, $\mathrm{c}=0.398 \mathrm{mM}$ ) and TIOAc (bottom, $\mathrm{c}=0.387 \mathrm{mM}$ ) were added at 3 min intervals. The concentration of $\mathrm{RbCl}$ was: top right, $\mathrm{c}=0.500 \mathrm{mM}$; bottom, $\mathrm{c}=0.911$ $\mathrm{mM}$ (competition experiments). 

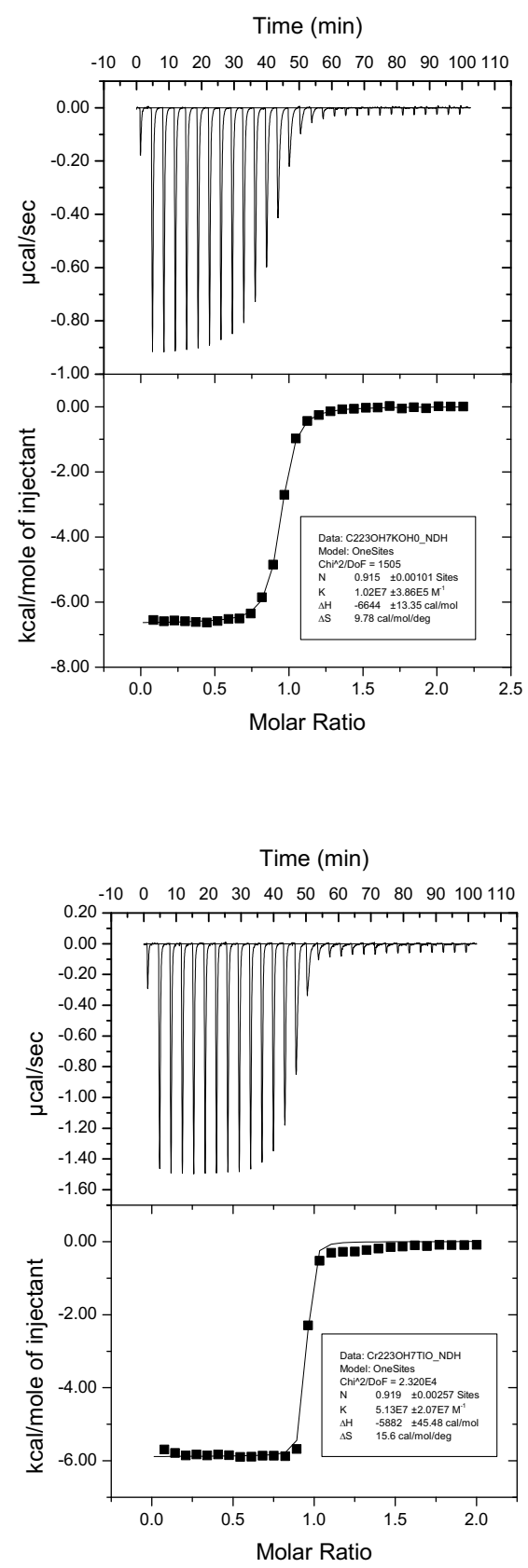

Figure S14: Calorimetric titration of 1 in $\mathrm{KOH} / \mathrm{H}_{2} \mathrm{O}(0.1 \mathrm{M})$ at $298 \mathrm{~K}$ in presence $\mathrm{CsOH}$ (top) or TIOAc (bottom). The host solution (top, $\mathrm{c}=40.2 \mu \mathrm{M}$; bottom, $\mathrm{c}=75.4 \mu \mathrm{M}$ ) was placed into the calorimeter cell $(1.4 \mathrm{~mL})$ and 28 successive aliquots $(10 \mu \mathrm{L})$ of $\mathrm{CsOH}$ (top, $\mathrm{c}=0.400 \mathrm{mM}$ ) and TIOAc (bottom, $\mathrm{c}=$ $0.693 \mathrm{mM}$ ) were added at $3 \mathrm{~min}$ intervals. 

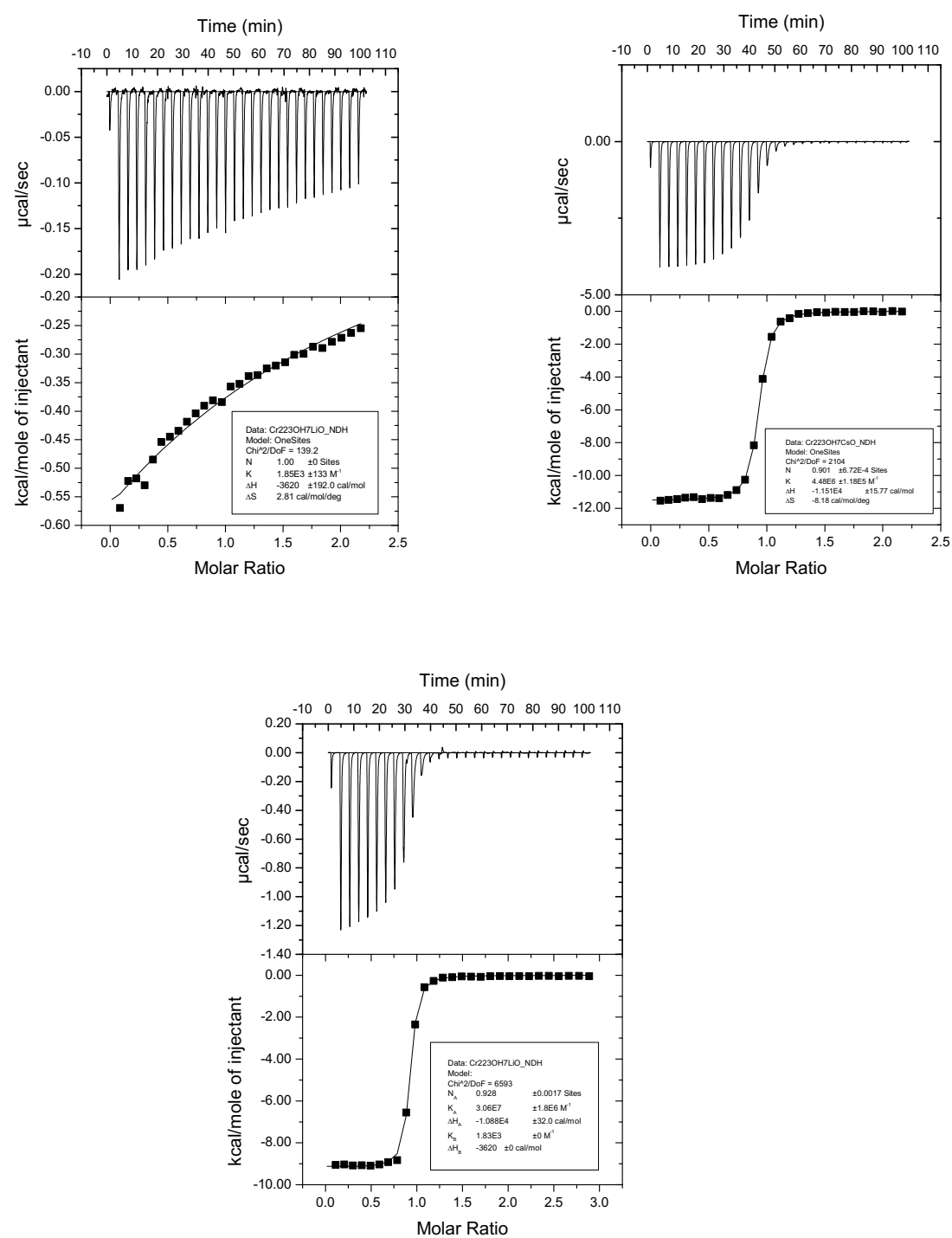

Figure S15: Calorimetric titration of 1 in $\mathrm{LiOH} / \mathrm{H}_{2} \mathrm{O}(1 \mathrm{M})$ at $298 \mathrm{~K}$ in presence (or not) of $\mathrm{RbCl}$ (top left), $\mathrm{CsOH}$ (top right) or TIOAc (bottom). The host solution (top left, $\mathrm{c}=98.2 \mu \mathrm{M}$; top right, $\mathrm{c}=99.1$ $\mu \mathrm{M}$; bottom, $\mathrm{c}=29.8 \mu \mathrm{M})$ was placed into the calorimeter cell $(1.4 \mathrm{~mL})$ and 28 successive aliquots $(10$ $\mu \mathrm{L}$ ) of $\mathrm{RbCl}$ (top left $\mathrm{c}=1.029 \mathrm{mM}$ ), $\mathrm{CsOH}$ (top right, $\mathrm{c}=0.986 \mathrm{mM}$ ) and $\mathrm{TIOAc}$ (bottom, $\mathrm{c}=0.493$ $\mathrm{mM}$ ) were added at 3 min intervals. 


$\begin{array}{ccccl}\mathrm{M}^{+} & \mathrm{LiOH} / \mathrm{H}_{2} \mathrm{O}(0.1 \mathrm{M}) & \mathrm{NaOH} / \mathrm{H}_{2} \mathrm{O}(0.1 \mathrm{M}) & \mathrm{KOH} / \mathrm{H}_{2} \mathrm{O}(0.1 \mathrm{M}) & \mathrm{LiOH} / \mathrm{H}_{2} \mathrm{O}(1 \\ & \Delta H^{0}=-5.1 & \Delta H^{0}=-4.4 & & \\ \mathrm{Rb}^{+} & \Delta S^{0}=+6.3 & \Delta S^{0}=10.0 & \text { Not measured } & \Delta H^{0}=-3.6 \\ & \Delta G^{0}=-7.0 & \Delta G^{0}=-7.4 & & \Delta S^{0}=+2.8 \\ & & & & \Delta G^{0}=-4.5 \\ \mathrm{Cs}^{+} & \Delta H^{0}=-11.8 & \Delta H^{0}=-11.0 & \Delta H^{0}=-6.6 & \Delta H^{0}=-11.5 \\ & \Delta S^{0}=-0.2 & \Delta S^{0}=+3.6 & \Delta S^{0}=+9.8 & \Delta S^{0}=-8.2 \\ & \Delta G^{0}=-11.7 & \Delta G^{0}=-12.1 & \Delta G^{0}=-9.6 & \Delta G^{0}=-9.1 \\ \mathrm{Tl}^{+} & \Delta H^{0}=-10.4 & \Delta H^{0}=-10.2 & \Delta H^{0}=-5.9 & \Delta H^{0}=-10.9 \\ & \Delta S^{0}=+10.8 & \Delta S^{0}=+11.7 & \Delta S^{0}=+15.8 & \Delta S^{0}=-2.2 \\ & \Delta G^{0}=-13.6 & \Delta G^{0}=-13.7 & \Delta G^{0}=-10.6 & \Delta G^{0}=-10.2\end{array}$

Figure S16: Thermodynamic parameters $\Delta H^{0}\left(\mathrm{kcal} \mathrm{mol}^{-1}\right), \Delta S^{0}\left(\mathrm{cal} \mathrm{mol}^{-1} \mathrm{~K}^{-1}\right)$ and $\Delta G^{0}\left(\mathrm{kcal} \mathrm{mol}^{-1}\right)$ of the $\mathrm{M}^{+} @ 1$ complexes $\left(\mathrm{M}^{+}=\mathrm{Rb}^{+}, \mathrm{Cs}^{+}, \mathrm{TI}^{+}\right)$in $\mathrm{LiOH} / \mathrm{H}_{2} \mathrm{O}(0.1 \mathrm{M}$ and $1 \mathrm{M}), \mathrm{NaOH} / \mathrm{H}_{2} \mathrm{O}(0.1 \mathrm{M})$ and $\mathrm{KOH} / \mathrm{H}_{2} \mathrm{O}(0.1 \mathrm{M})$ solutions. 


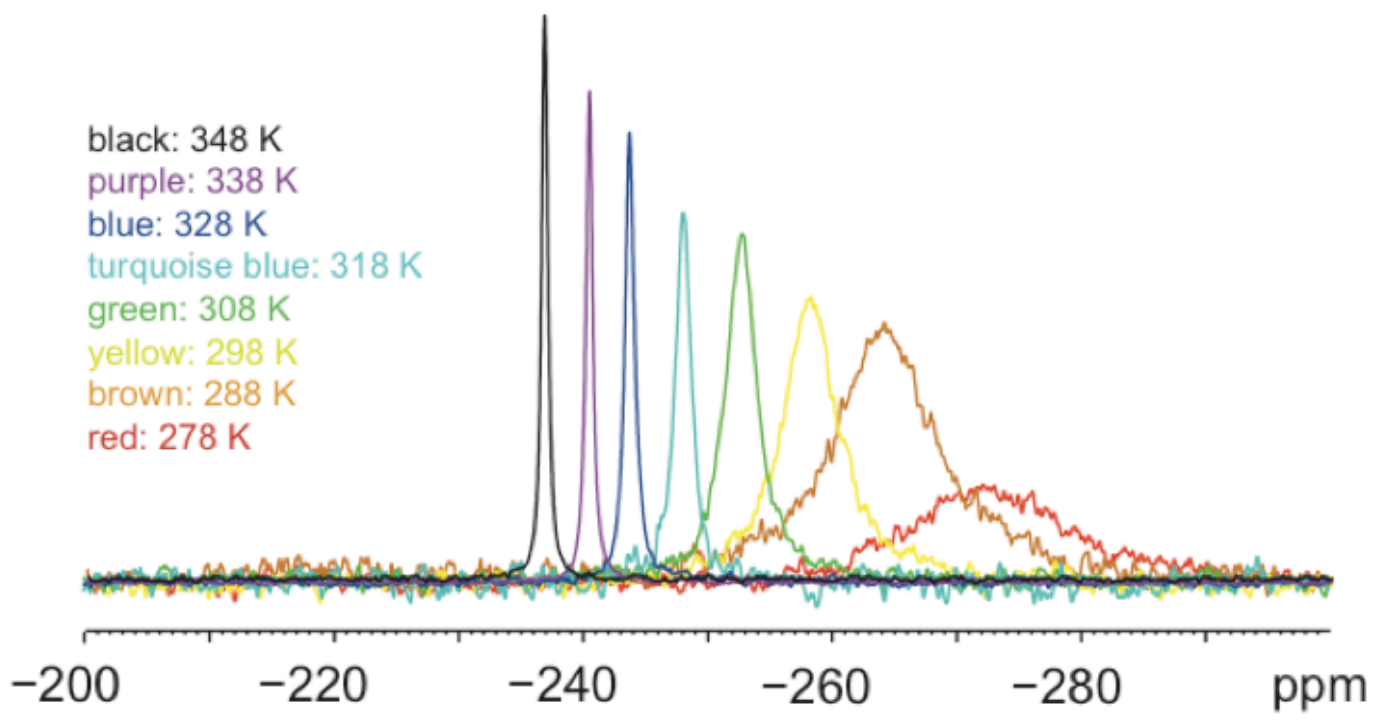

Figure S17: ${ }^{133} \mathrm{Cs}$ NMR spectra of the $\mathrm{Cs}^{+} @(r a c)-1$ complex in $\mathrm{NaOD} / \mathrm{D}_{2} \mathrm{O}(0.1 \mathrm{M})$ at different temperatures: $278,288,298,308,318,328,338$ and $348 \mathrm{~K}$. 

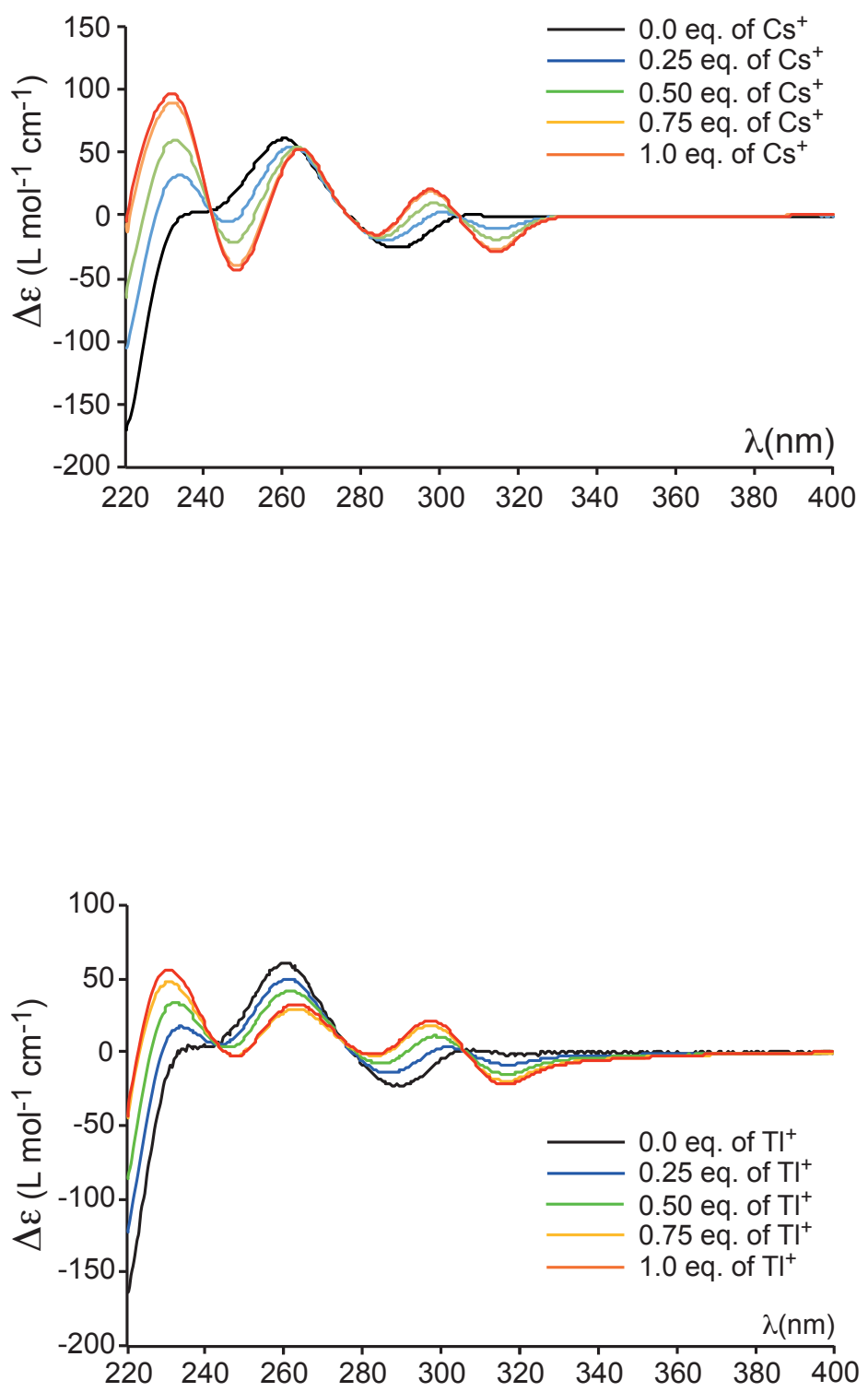

Figure S18: ECD spectra recorded at $293 \mathrm{~K}$ of $\mathrm{MM}-1$ in $\mathrm{LiOH} / \mathrm{H}_{2} \mathrm{O}(0.1 \mathrm{M})$ solution (saturated with $\mathrm{CHCl}_{3}$ ) in presence of different amount of a) top spectra: cesium hydroxide. b) bottom spectra: thallium acetate solutions. [Host] was $1.310^{-5} \mathrm{M}$ for a) [Host] was $1.3510^{-5} \mathrm{M}$ for b). ECD spectra for higher $\left[\mathrm{Cs}^{+}\right]\left(\left[\mathrm{TI}^{+}\right]\right)$are identical to that recorded for 1 eq. of $\mathrm{Cs}^{+}\left(\mathrm{TI}^{+}\right)$. 

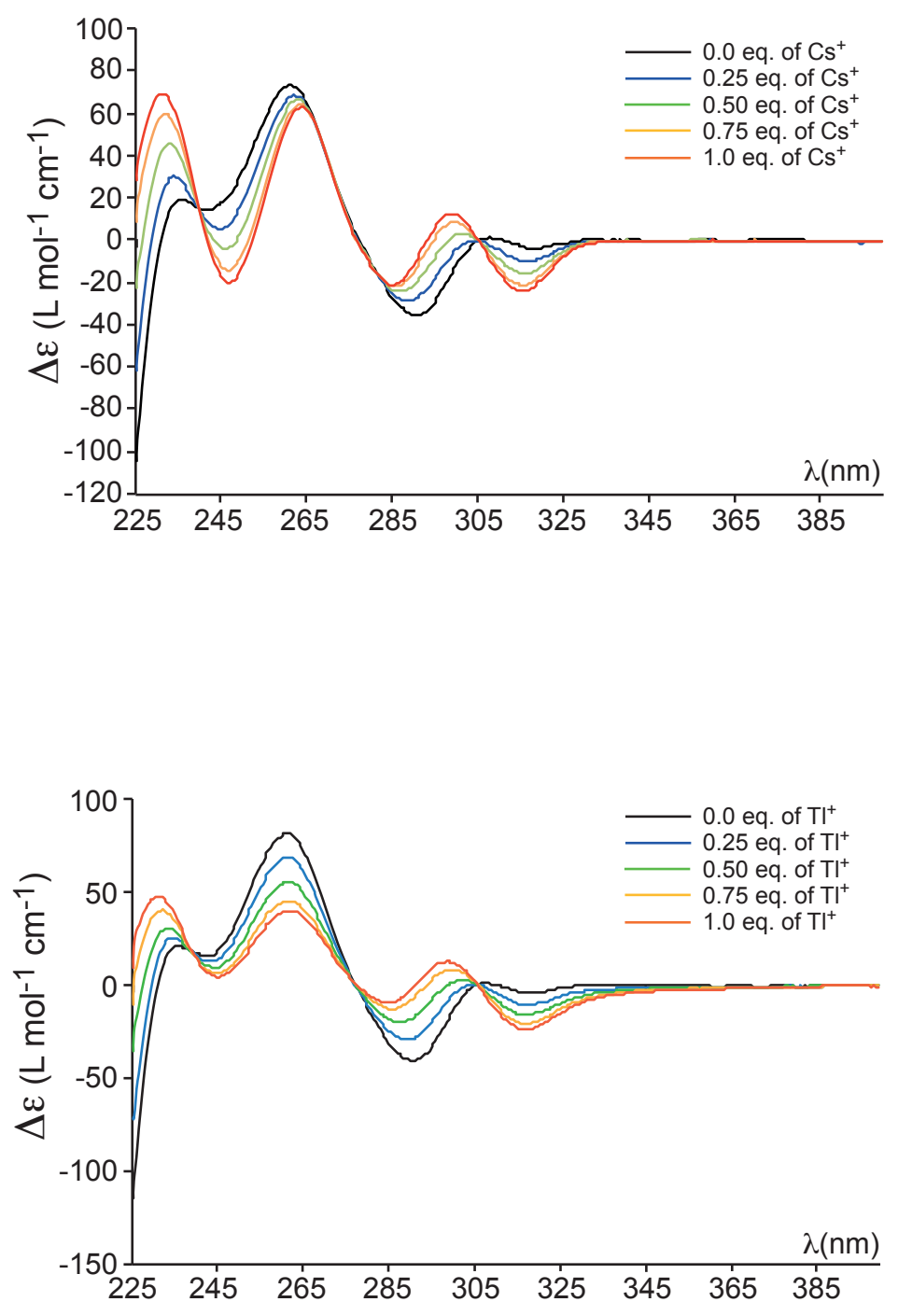

Figure S19: ECD spectra recorded at $293 \mathrm{~K}$ of $M M-1$ in $\mathrm{LiOH} / \mathrm{H}_{2} \mathrm{O}(1 \mathrm{M})$ in presence of different amount of a) top spectra: cesium hydroxide. b) bottom spectra: thallium acetate solutions. [Host] was $1.4510^{-5} \mathrm{M}$ for a) [Host] was $1.310^{-5} \mathrm{M}$ for b). ECD spectra for higher $\left[\mathrm{Cs}^{+}\right]\left(\left[\mathrm{TI}^{+}\right]\right)$are identical to that recorded for 1 eq. of $\mathrm{Cs}^{+}\left(\mathrm{Tl}^{+}\right)$. 

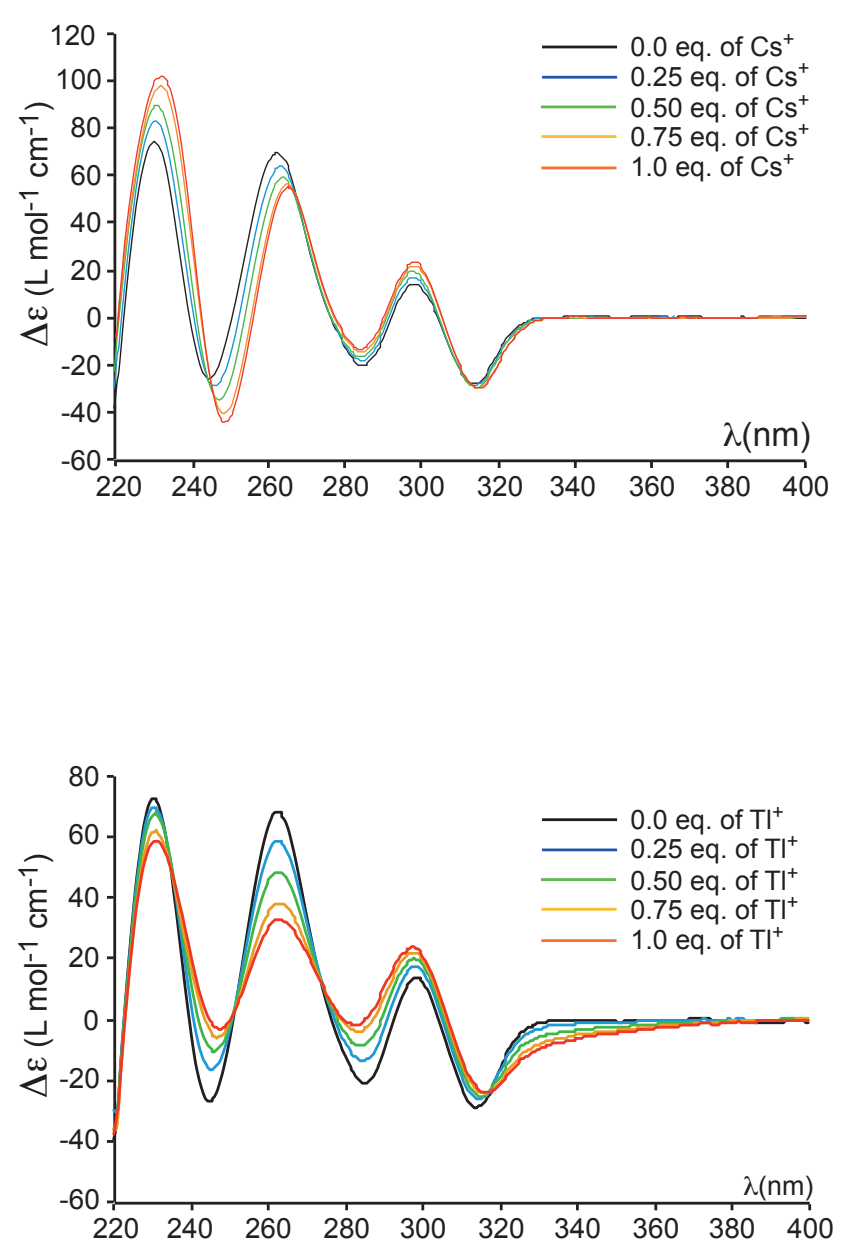

Figure S20: ECD spectra recorded at $293 \mathrm{~K}$ of $M M-1$ in $\mathrm{KOH} / \mathrm{H}_{2} \mathrm{O}(0.1 \mathrm{M})$ solution in presence of different amount of a) top spectra: cesium hydroxide. b) bottom spectra: thallium acetate solutions. [Host] was $1.310^{-5} \mathrm{M}$ for a) [Host] was $1.310^{-5} \mathrm{M}$ for b). ECD spectra for higher [Cs $\left.{ }^{+}\right]\left(\left[\mathrm{TI}^{+}\right]\right)$are identical to that recorded for 1 eq. of $\mathrm{Cs}^{+}\left(\mathrm{Tl}^{+}\right)$. 


\section{Computational details}

\section{Geometry}

Geometry optimizations of the $\mathrm{M}^{+}(\mathrm{M}=\mathrm{K}, \mathrm{Rb}, \mathrm{Cs}, \mathrm{TI})$ encapsulated in the cryptophane cage were performed using density functional theory (DFT) with the ORCA 3.03 program package along with the Resolution of Identity approximation.[8,9] The near-field Coulomb interactions are evaluated employing the RI-J approximation. It speeds up calculation of the Coulomb term for large systems.

The B97-D functional was considered corrected by the empirical dispersion term (D3) proposed by Grimme et al. with a finite damping as introduced by Becke and Johnson (BJ-damping) to account for the London dispersion energy. $[10,11]$ The addition of the BJ-damping provides better results for nonbonded distances and more clear effects of intramolecular dispersion. The split valence plus polarization triple- $\zeta$ (def2-TZVP) basis set was used for $\mathrm{H}, \mathrm{Li}, \mathrm{C}, \mathrm{O}$. [12] For the alkali metal series and $\mathrm{Tl}$ atom, we used the segmented all-electron relativistically contracted (SARC) basis sets in conjunction with a scalar relativistic Hamiltonian. [13] In the present work, we applied two-component relativistic DFT approach based on the zero-order regular approximation (ZORA). [14]

\section{Energy decomposition analysis (EDA)}

Analysis of the chemical interactions can be performed combining a fragment approach to the molecular structure of the complex with the decomposition of the total bonding energy into separate components familiar to chemists:

$$
\Delta E_{\text {int }}=\Delta E_{\text {el. }}+\Delta E_{\text {rep. }}+\Delta E_{\text {orb. }}
$$

The interaction energy $E_{\text {int. }}$ between two fragments $A$ and $B$ in a molecular system $A-B$ is partitioned in three terms, namely, (1) the quasiclassical electrostatic interaction $E_{\text {el. }}$ between the fragments, (2) the repulsive exchange (Pauli) interaction $E_{\text {rep. }}$ between electrons of the two fragments having the same spin, and (3) the orbital (covalent) interaction $E_{o r b}$, which comes from the orbital relaxation and the orbital mixing between the fragments. [15] 
The computations were performed with ADF 2016, ZORA-DFT/PBE-D3(BJ) and TZ2P all-electron relativistic basis sets at the ORCA geometries. [16] The fragment $\mathrm{M}^{+}$and the cryptophane cage were considered for the EDA.

\section{Non Covalent Interaction (NCI)}

Johnson and co-workers recently introduced a method for studying non-covalent interactions ( $\mathrm{NCls}$ ) based on the electron density $(\rho)$, the reduced gradient of the density $\left(s=|\nabla \rho| /\left(2\left(3 \pi^{2}\right)^{1 / 3} \rho^{4 / 3}\right)\right.$, and the Laplacian of the density $\left(\nabla^{2} \rho\right)$.[17] The approach allows one to identify the interactions in realspace, thus enabling a graphical visualization of the regions where non-covalent interactions occur. To recover most of the interaction in the real space, explicitly correlated methods are required. In this work, we performed single-point DLPNO-CCSD $(\mathrm{T})$ calculations with ORCA 3.03 program package and the relativistic Hamiltonian and basis set described previously. [18] The non-covalent interaction plots were produced with MULTIWFN and VMD. $[19,20]$

\section{Orbital mixing}
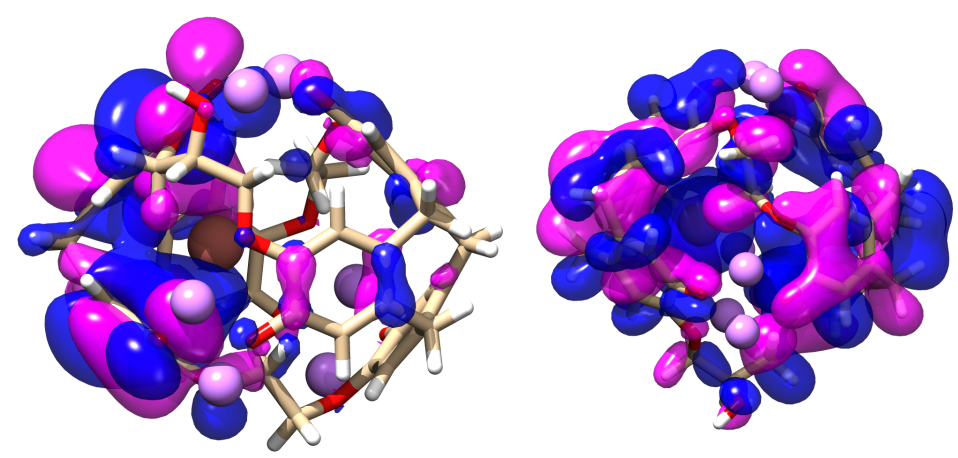

Figure a: mixing of the $6 \mathrm{p}(\mathrm{TI})$ (left) and the $6 \mathrm{~s}(\mathrm{TI})$ (right) orbitals with the cryptophane orbitals

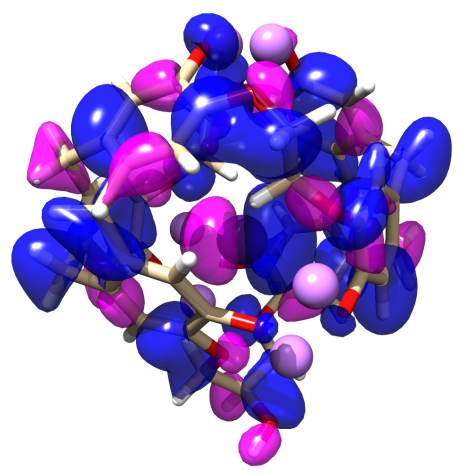

Figure b: mixing of the $5 p(C s)$ orbital with the cryptophane orbitals 


\section{Nuclear magnetic shielding}

The $\mathrm{M}^{+}$isotropic shielding was calculated through the DFT/GIAO shielding tensor, the formal definition of its components being:[21]

$$
\sigma_{\alpha \beta}=\frac{\partial^{2} E}{\partial \mu_{\alpha} \partial B_{\beta}}
$$

where $E$ is the total electronic energy of the molecule; $B$ is the external magnetic field and $\mu$ is the magnetic moment of the nucleus of interest.

The $\mathrm{M}^{+}$nuclear magnetic shielding tensor was computed at the ORCA geometries with DFT and a PBE functional using Gauge-Including Atomic Obitals (GIAO) method as implemented in ADF 2016.[22] Slater-type orbitals (STOs) were employed as basis functions in SCF calculations. The allelectron valence triple zeta, polarized relativistic basis set TZ2P was used for all atoms. Scalar and spin-orbit coupling relativistic effects were considered using the zero-order regular approximation (ZORA). In practical applications calculations using GIAOs usually produce better results with small or medium basis sets that are mandatory for our large size systems.

To reduce systematic errors in calculating the NMR chemical shifts, a secondary reference was used.

The NMR chemical shifts (in ppm) were obtained using the equation:

$$
\delta_{i}=\sigma_{\text {ref. }}-\sigma_{i}+\delta_{\text {ref }} .
$$

where $\sigma_{\text {ref. }}$ is the calculated NMR shielding of the corresponding nucleus in the reference compound ( $\mathrm{M}^{+}$in vacuum), $\sigma$ is the calculated NMR shielding of the investigated nucleus ( $\mathrm{M}^{+}$in the complex), and $\delta_{r e f}$. is the experimental NMR chemical shift of the secondary reference relative to the primary standard. For $\mathrm{Tl}^{+}$and $\mathrm{Cs}^{+}$the secondary references are $\mathrm{TINO}_{3}$ and $\mathrm{CsNO}_{3}$ in $\mathrm{D}_{2} \mathrm{O}$ respectively. For $\mathrm{TI}^{+}$ $\delta_{\text {ref. }}=340 \mathrm{ppm}$ and for $\mathrm{Cs}^{+} \delta_{\text {ref. }}=0 .[23]$

\section{REFERENCES:}

\section{Experimental section :}

[1]T. Buffeteau, F. Lagugné-Labarthet, C. Sourrisseau, Appl. Spectrosc. 2005, 59, 732-745.

[2]T. Brotin, D. Cavagnat, P. Berthault, R. Montserret, T. Buffeteau, J. Phys. Chem. B 2012, 116, 10905.

[3]F. Neese, "The ORCA program system", Wiley interdisciplinary Reviews - Computational Molecular Science, 2012, 2, 73.

[4]ADF2016, SCM, Theoretical Chemistry, Vrije Universiteit, Amsterdam, The Netherlands, http://www.scm.com, 2016.

[5]E. V. Lenthe, E. J. Baerends, J. G. Snijders, J. Chem. Phys. 1993, 99, 4597.

[6]T. Lu, F. Chen, J. Comput. Chem.2012, 33, 580.

[7]W. Humphrey, A. Dalke, K. Schulten, J. Mol. Graph.1996, 14, 33. 


\section{Computational details:}

[8] Neese, F. "The ORCA program system", Wiley interdisciplinary Reviews - Computational Molecular Science, 2012, 2, 73.

[9] Vahtras, O., Almlöf, J., Feyereisen, M. W., Chem. Phys. Lett., 1993, 213, 514.

[10] Grimme S., Antony J., Ehrlich S., Krieg H., J. Chem. Phys., 2010, 132, 154104.

[11] Grimme S., Ehrlich S., Goerigk L., J. Comput. Chem., 2011, 32, 1456.

[12] Weigend F., Ahlrichs R., Phys. Chem. Chem. Phys., 2005, 7, 3297.

[13] a) Pantazis D. A. and Neese F., J. Chem. Theory Comput., 2009, 5, 2229. b) Pantazis D. A. and Neese F., Theor. Chem. Acc., 2012, 131, 1292.

[14] van Wuellen C., J. Chem. Phys., 1998, 109, 392.

[15] Hopffgarten M. von, Frenking G., WIREs Comput. Mol. Sci., 2012, 2, 43.

[16] ADF2016, SCM, Theoretical Chemistry, Vrije Universiteit, Amsterdam, The Netherlands, http://www.scm.com, 2016.

[17] Johnson E. R., Keinan S., Mori-Sanchez P., Contreras-Garcia J., Cohen A. J., Yang W., J. Am. Chem. Soc., 2010, 132, 6498.

[18] a) Riplinger, C., Neese, F., J. Chem. Phys., 2013, 138, 034106. b) Riplinger, C., Sandhoefer, B., Hansen, A., Neese, F., J. Chem. Phys., 2013, 139, 134101.

[19] Lu T., Chen F., J. Comput. Chem., 2012, 33, 580.

[20] Humphrey, W., Dalke, A. and Schulten, K., "VMD - Visual Molecular Dynamics", J. Molec. Graphics, 1996, 14, 33.

[21] a) Schreckenbach G., Ziegler T., J. Phys. Chem., 1995, 99, 606-611. b) Schreckenbach G., Ziegler T., Int. J. Quantum Chem., 1997, 61, 899.

[22] te Velde G., Bickelhaupt F. M., Baerends E. J., Guerra C. F., Van Gisbergen S. J. A., Snijders J. G., Ziegler T., J. Comput. Chem., 2001, 22, 931.

[23] T. Brotin, S. Goncalves, P. Berthault, D. Cavagnat, T. Buffeteau, J. Phys. Chem. B 2013, 117, 12593. 